Discussion

Papers

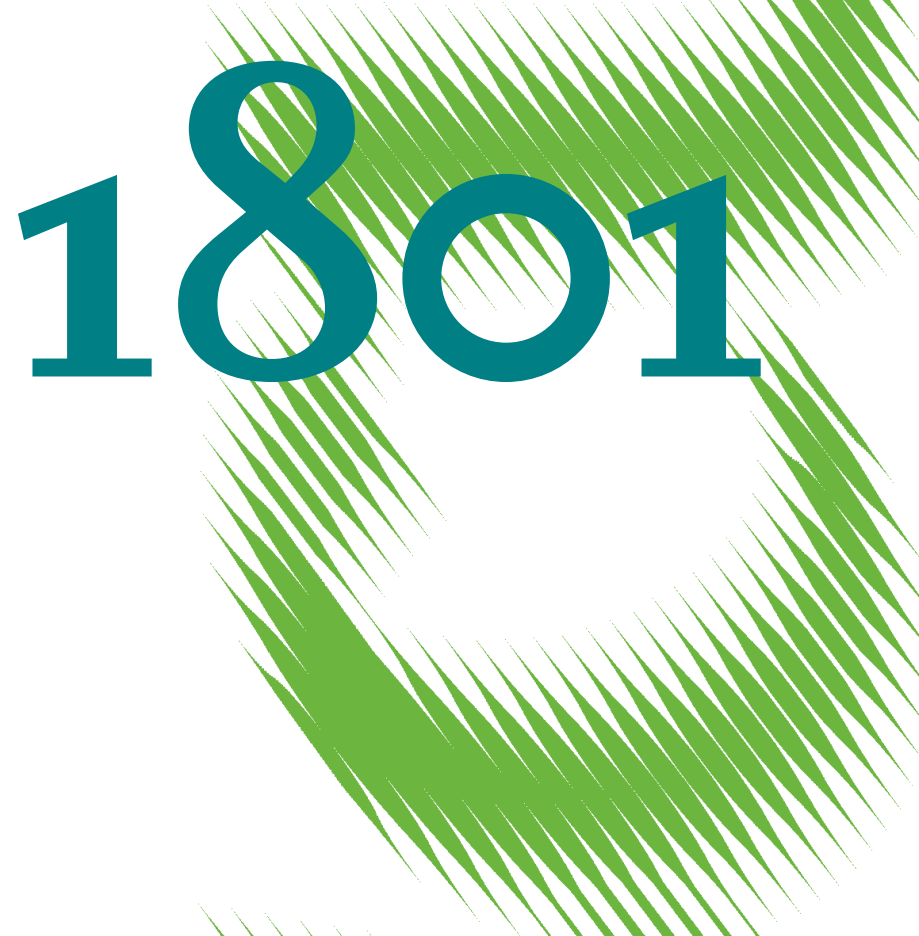

Strategic Environmental Policy and the Mobility of Firms 
Opinions expressed in this paper are those of the author(s) and do not necessarily reflect views of the institute.

IMPRESSUM

(C) DIW Berlin, 2019

DIW Berlin

German Institute for Economic Research

Mohrenstr. 58

10117 Berlin

Tel. +49 (30) $89789-0$

Fax +49 (30) $89789-200$

http://www.diw.de

ISSN electronic edition 1619-4535

Papers can be downloaded free of charge from the DIW Berlin website:

http://www.diw.de/discussionpapers

Discussion Papers of DIW Berlin are indexed in RePEc and SSRN:

http://ideas.repec.org/s/diw/diwwpp.html

http://www.ssrn.com/link/DIW-Berlin-German-Inst-Econ-Res.html 


\title{
Strategic Environmental Policy and the Mobility of Firms ${ }^{1}$
}

\author{
Philipp M. Richter \\ TU Dresden, CESifo, DIW Berlin, KCG \\ Marco Runkel \\ TU Berlin, CESifo, NoCeT \\ Robert C. Schmidt \\ FernUniversität in Hagen
}

March 12, 2019

\begin{abstract}
The loss of international competitiveness of domestic industries remains a key obstacle to the implementation of effective carbon prices in a world without harmonized climate policies. We analyze countries' non-cooperative choices of emissions taxes under imperfect competition and mobile polluting firms. In our general equilibrium setup with trade, wage effects prevent all firms from locating in the same country. While under local or no pollution countries achieve the first-best, under transboundary pollution taxes are inefficiently low and lower than under autarky where only the 'standard' free-riding incentive distorts emissions taxes. This effect is more pronounced when polluting firms are mobile.
\end{abstract}

JEL classification: F12, F18, H23

Keywords: $\quad$ Strategic Environmental Policy, Firm Location, Carbon Leakage, General Equilibrium

\footnotetext{
${ }^{1}$ Richter: Faculty of Business and Economics, Technische Universität Dresden, Helmholtzstr. 10, 01069 Dresden, and DIW Berlin department of Energy, Transportation, Environment, Mohrenstr. 58, 10117 Berlin, Germany, Email: philipp_moritz.richter@tu-dresden.de; Runkel: Faculty of Economics and Management, Technische Universität Berlin, Straße des 17. Juni 135, H51, 10623 Berlin, Germany, Email: marco.runkel@tu-berlin.de; Schmidt: Faculty of Business Administration and Economics, FernUniversität in Hagen, Universitätsstr. 11, 58097 Hagen, Germany; Email: robert.schmidt@fernuni-hagen.de.
} 


\section{Introduction}

In the absence of a harmonized global climate policy, the success of humankind to avoid dangerous levels of climate change relies on decentralized policy-setting. There is strong evidence that current policy initiatives in the form of nationally determined contributions pursuant to the Paris Agreement fall short of leading to pathways that limit global warming to 'well below $2^{\circ} \mathrm{C}$ ' (cf. IPCC, 2018). Even countries with high public support for ambitious climate policy weigh the benefits of unilateral efforts to reduce their emissions against the domestic costs and strategic industrial policy motives in a globalized world. The problem may even be more severe than suggested by the well-known free-rider incentive, according to which individual countries neglect the positive environmental externalities of their own abatement efforts upon other countries, while enjoying the benefits of the others' efforts. Ambitious unilateral climate policy may also lead to deindustrialization and the relocation of domestic firms to regions with lower environmental standards.

In this paper, we shed new light on the strategic effects of the (non-cooperative) decentralized choice of emissions taxes, with a particular focus on the role of international mobility of polluting firms. We first demonstrate that decentralized policy-setting does not necessarily lead to an inefficient outcome. Both in the absence of environmental damage as well as under local pollution, the outcome under strategic policy-setting coincides with the (cooperative) first-best policy. Remarkably, this result holds even if firms are mobile. Under transboundary pollution, by contrast, tax rates are chosen inefficiently low under decentralization, and firm mobility aggravates this inefficiency. We also show that the non-cooperative tax rates are lower than in the autarky benchmark where all trade is prohibited, and policy-makers only neglect the environmental externalities due to the freeriding incentive. Our results thus show that with transboundary pollution, decentralized policy-making can lead to a worse outcome than suggested by the 'standard' free-rider argument, with the inefficiency being particularly pronounced when firms are mobile.

These results are brought forth in a two-country model where the governments of the countries play a non-cooperative Nash game in emissions tax rates on a general equilibrium of input and output markets. Each country hosts two sectors using labor as sole input in order to produce a numeraire good and a polluting good. While producers of the numeraire good act under perfect competition, the polluting good is produced by imperfectly competitive firms which are either mobile or immobile. In each country, 
the representative household uses profit, labor, and transfer income in order to finance consumption of the two goods. Its utility equals consumption utility less environmental damage. The government of each country imposes an emissions tax on the polluting sector. There are several important features of this framework which allow to derive the above-mentioned results and in combination render the model novel in comparison to the previous literature. First, we simultaneously allow for intensive (output) and extensive (location) margins of polluting firms. Second, due to the general equilibrium feature the wage rate is endogenous in each country. This is the reason why in the case of firm mobility we obtain an interior location equilibrium. Third, we consider an integrated market approach where all goods produced in the two countries are also consumed in these countries, avoiding the need for the assumption of a third country outside the model.

Within this framework, we first characterize the comparative static effects of emissions taxes on the market equilibrium. It turns out that an increase in one country's tax rate reduces emissions in this country and increases emissions in the other country (leakage) via corresponding changes in output. Leakage is incomplete, so total emissions from both countries fall. Under firm mobility the effects on emissions in both countries are larger in absolute terms, since leakage additionally takes place by relocation of firms. But the effect on total emissions is the same as in case with given firm location. Based on these insights, we show that the efficient (cooperative) policy equates the marginal consumption utility of the polluting good to the opportunity costs of a reduced consumption and utility of the numeraire good and the marginal environmental damage. By comparing this efficient solution with the countries' non-cooperative tax rate choice we prove our main results that non-cooperation is efficient if environmental pollution is absent or local and that with transboundary pollution the non-cooperative tax rates are inefficiently low, with a higher degree of inefficiency if firms are mobile instead of immobile.

In order to provide an intuition of these results, we consider the policy externality, i.e. the effect of one country's tax rate on welfare in the other country. This externality can be decomposed into two subexternalities. First, tax rate changes in one country change production patterns and thereby consumption possibilities in the other country, amounting to a consumption externality. Second, a change in one country's emissions tax rate affects pollution in the other country via emissions spill-overs and leakage, leading to a pollution externality. In the absence of pollution, the non-cooperative tax rates are 
efficient since the pollution externality vanishes and the consumption externality also becomes zero as it mirrors the Nash equilibrium condition. Under local pollution, the pollution externality is strictly negative since emissions spill-overs are not present and leakage causes an emissions increase in the foreign country. Moreover, the consumption externality turns out to be positive and equal to the pollution externality in absolute terms. Surprisingly, we thus obtain efficiency not because the non-cooperative tax rates do not cause cross-country effects, but since the two subexternalities exactly offset each other. While we show that under firm mobility the two subexternalities are both larger in absolute terms, the opposing effects still balance out and ensure efficiency. Finally, under transboundary pollution the sum of both externalities depends on the difference between the leakage effect and the own emissions effect of one country's tax rate. Since leakage is incomplete this difference is positive, implying inefficiently low tax rates under non-cooperation. As mentioned above, under firm mobility the gap between leakage and the effect on own emissions increases, explaining why firm mobility raises the policy externality and thereby aggravates the inefficiency of non-cooperative tax rates.

For further illustration, we discuss several features of our model. First, we consider the case of autarky, without trade between the two countries. Only emissions spill-overs prevail in this case, causing the free-rider incentive which renders the tax rates under autarky inefficiently low. But we show that the inefficiency is less pronounced under autarky than under non-cooperation with given firm location. Hence, our analysis reveals three sources of inefficiency: free-riding (efficiency versus autarky), strategic incentives (autarky versus non-cooperation with fixed location), and firm mobility (non-cooperation with fixed location versus non-cooperation with endogenous location). Second, we show that the endogeneity of wages tends to cushion the adverse welfare effects of non-cooperative policy making. The reason is that with endogenous wages the firms' output and emissions reaction to a tax rate increase is less elastic since the wage rate falls. Finally, imperfect competition turns out to be key to the result that firm mobility aggravates the policy inefficiency, since with perfect competition, after-tax profits are always zero in both countries, so none of the governments can attract firms by lowering tax rates.

Our paper contributes to various strands of literature. Most notably, we combine the literature on strategic environmental policy and the literature on environmental policy with firm location in order to show how firm mobility amplifies the welfare losses when 
countries act strategically and do not cooperate in their policy choices. More specific, the literature on strategic environmental policy was pioneered by Conrad (1993), Kennedy (1994), Hung (1994), and Barrett (1994). Surveys can be found in, e.g., Sturm (2003) and Requate (2006). One basic insight of this literature is that governments may set their emissions tax rates inefficiently low in order to capture foreign rents and increase the domestic firms' market share. We complement this result by distinguishing between intensive and extensive margins of polluting firms and showing that firm mobility exacerbates the inefficiency. Interestingly, there are also papers that similar to us derive efficiency of decentralized policy if pollution is local. This is true, for instance, in Kennedy (1994) for perfect competition, in Duval and Hamilton (2002) for balanced trade, in Hamilton and Requate (2004) for a model where firms dispose of vertical contracts with a two-part tariff, and in Oates and Schwab (1988) for a capital tax competition framework. ${ }^{1}$ But again, these articles ignore the extensive margin of polluting firms, so our contribution is to show that firm mobility does not change the efficiency outcome under local pollution. Moreover, none of the aforementioned articles uses a general equilibrium structure and, thus, cannot show that the endogeneity of wage rates tends to cushion the inefficiency of decentralized emissions tax policy, which is a further contribution of our paper.

The literature on environmental policy in the presence of mobile firms was initiated by the seminal paper of Markusen et al. (1993), who analyze location of two polluting firms in a two-country model. In Markusen et al. (1995), the authors even endogenize both countries' tax rates, but restrict their attention to a monopolistic industry structure. While relevant for our analysis, there is a fundamental difference of this literature to our approach. Most of the existing models assume transportation costs to explain why firms have an incentive to choose locations close to markets they serve. It is a common finding that in the absence of transportation costs, relocation leads to the concentration of firms in one country (cf. Hoel, 1997; Rauscher, 1995). We rarely observe such location patterns, even though transportation costs have substantially declined in many markets due to globalization. Moreover, the assumption of transportation costs leads to increased complexity that confines previous studies to numerical analyses (cf. Markusen et al.,

\footnotetext{
${ }^{1}$ Ogawa and Wildasin (2009) confirm the efficiency result of Oates and Schwab (1988) even for transboundary pollution. But Eichner and Runkel (2012) prove that efficiency in this case is contingent on the capital supply elasticity to be zero, which corresponds to fixed total emissions. Eichner and Runkel (2014) show inefficiency in a similar model with the additional policy instrument of subsidies on renewables.
} 
1993). In our model, by contrast, an interior location equilibrium is ensured by the general equilibrium property of an endogenous wage rate, which has several advantages over the assumption of transportation costs. For instance, it ensures tractability under general functional forms of the model primitives, and it allows to investigate the impact of endogenous wage rates on the inefficiency of decentralized environmental policy.

We finally have to mention the link of our paper to the literature on strategic trade policy initiated by, e.g., Brander and Spencer (1985), and surveyed by Brander (1995). In fact, our special case without pollution is a model on strategic trade policy. It is a common finding in the trade literature that, due to rent-seeking motives, non-cooperative policy usually does not coincide with the cooperative policy (Brander, 1995). Hence, our efficiency result in the absence of pollution comes as a surprise. But this difference in results can be explained by the difference in modeling consumption markets. While comparable papers in the trade policy literature, like Brander and Spencer (1985), derive the inefficiency result under the 'third-country' assumption where all firms sell their output in a third country not explicitly modeled, we consider an 'integrated market' approach where all goods produced in the two countries are also consumed in these countries. We explicitly show in our discussion section, that our efficiency result in the absence of environmental pollution breaks down if we introduce the third country assumption. ${ }^{2}$

The remainder of the paper is organized as follows. Section 2 describes our basic model. Section 3 presents the cooperative and non-cooperative policy solutions. In Section 4 , we show additional results by relaxing key assumptions. Section 5 concludes.

\section{Model}

Basic Structure. We consider a model with two countries, $A$ and $B$. Both countries host production sectors for good $X$ and good $Y$ which use labor as sole input. Labor is mobile across sectors and immobile across countries. Moreover, firms in the $X$-sector are immobile, whereas we distinguish the cases with mobile and immobile firms in sector

\footnotetext{
${ }^{2}$ Technically, our paper is also related to the paper of Haufler and Wooton (2010) who take into account endogenous firm location in analyzing the impact of economic integration on decentralized subsidy choice by governments. But they, too, consider transportation costs instead of endogenous wage rates as reason for an interior location equilibrium. Moreover, they focus on the extensive margin, while we analyze both extensive and intensive margins and additionally consider pollution and environmental policy.
} 
$Y$. Production of good $Y$ generates emissions that cause local or global environmental damage. Both goods are traded on an integrated 'world' market between the two countries without transportation costs, so prices are equalized across countries. We choose good $X$ as numeraire. Each country is populated by a representative household which owns labor endowment as well as the firms located in its country and uses total income to finance consumption of good $X$ and good $Y$. Utility is determined by consumption utility less environmental damage. Each government taxes emissions of domestic firms in the $Y$-sector and redistributes the revenues to the household in its country by a lump sum transfer. The timing is that governments first choose their tax policy, then firms make their location decision (if this decision is endogenous) and, finally, households and firms decide on consumption and production. We solve the model by backward induction.

Households. Consumption utility of the household in country $i \in\{A, B\}$ is given by

$$
U\left(x_{i}, y_{i}\right)=x_{i}+Z\left(y_{i}\right)
$$

where $x_{i}$ and $y_{i}$ is household $i$ 's consumption of good $X$ and good $Y$, respectively. The function $Z$ has the standard properties $Z^{\prime}>0>Z^{\prime \prime}$. Moreover, we assume either $Z$ and its derivatives to be monotone, or consider the special case of a quadratic $Z$, so $Z^{\prime \prime \prime} \geq 0$. $^{3}$

The household in country $i$ receives the wage rate $w_{i}$ from inelastically supplying one unit of labor as well as profit income $\Pi_{i}^{x}$ and $\Pi_{i}$ from owning the domestic firms in sector $X$ and sector $Y$, respectively. ${ }^{4}$ The lump sum transfer from the government reads $T_{i}$. Denoting the price of good $Y$ by $p$, the budget constraint of the household in country $i$ is

$$
x_{i}+p y_{i}=w_{i}+\Pi_{i}^{x}+\Pi_{i}+T_{i} .
$$

It equates consumption expenditures for good $X$ and good $Y$ to wage income, profit income and transfer income of the household in country $i$.

The household chooses $x_{i}$ and $y_{i}$ in order to maximize (1) subject to (2). The firstorder condition $p=Z^{\prime}\left(y_{i}\right)$ yields the demand function $y_{i}=Z^{\prime-1}(p)$. Aggregate demand from both countries reads $y_{i}+y_{j}=2 Z^{\prime-1}(p)$. If we denote the aggregate quantity of good

\footnotetext{
${ }^{3}$ Monotonicity of $Z$ and its derivatives together with $Z^{\prime}>0>Z^{\prime \prime}$ implies alternating signs of the derivatives of $Z$, see Menegatti (2001). Note that this assumption together with the quadratic case encompasses most functional specifications usually employed in economic models.

${ }^{4}$ To simplify later notation, we omit the superscript $y$ at all variables pertaining to sector $Y$.
} 
$Y$ supplied by the firms in country $i$ by $Q_{i}$, the equilibrium condition on the world market for good $Y$ is given by $Q_{i}+Q_{j}=y_{i}+y_{j}=2 Z^{\prime-1}(p)$ or, equivalently,

$$
p=Z^{\prime}\left(\frac{Q_{i}+Q_{j}}{2}\right)=: P\left(Q_{i}+Q_{j}\right) .
$$

Equation (3) represents the inverse demand function for good $Y$. This function satisfies $P^{\prime}=Z^{\prime \prime} / 2<0$ and $P^{\prime \prime}=Z^{\prime \prime \prime} / 4 \geq 0$. Moreover, we assume $P^{\prime}+q_{i \ell} P^{\prime \prime}<0$, where $q_{i \ell}$ is output of firm $\ell$ in the $Y$-Sector of country $i$. According to Dixit (1986), in the standard Cournot oligopoly this condition is sufficient for the second-order condition of profit maximization, for a negative slope of the firms' reaction functions (output levels are strategic substitutes) and for stability of the equilibrium. In an online appendix we show that the condition has the same implications in our model.

Non-polluting sector and labor market. The number of firms in the non-polluting $X$-sector is assumed to be large, so each individual firm acts as price taker both on the input market and the output market. For notational convenience, we normalize the number of $X$-firms to unity in each country. In country $i$, the $X$-firm uses the technology

$$
Q_{i}^{x}=c L_{i}^{x}+\delta F\left(L_{i}^{x}\right)
$$

where $Q_{i}^{x}$ is output and $L_{i}^{x}$ labor input. The production technology $F$ satisfies $F^{\prime}>0>$ $F^{\prime \prime}$. As with respect to $Z$, we consider either $F$ and its derivatives to be monotone or the special case of a quadratic $F$, so $F^{\prime \prime \prime} \geq 0$. The parameters $c \geq 0$ and $\delta \geq 0$ are introduced for technical reasons. For $\delta=0$ the wage rate $w_{i}$ will be given by $c$, as we shall see below in Section 4. Hence, our model encompasses the case of a fixed wage rate as special case. This will be useful for comparing our analysis to previous studies. However, the main focus of our analysis is the model specification with $\delta>0$ and an endogenous wage rate.

Profit of the firm in sector $X$ of country $i$ reads

$$
\Pi_{i}^{x}=c L_{i}^{x}+\delta F\left(L_{i}^{x}\right)-w_{i} L_{i}^{x}
$$

Profit maximization yields $w_{i}=c+\delta F^{\prime}\left(L_{i}^{x}\right)$, which is the inverse labor demand function of sector $X$ in country $i$. Since we will assume a one-to-one production technology in the $Y$-sector, labor demand of the $Y$-sector in country $i$ equals this sector's aggregate output 
$Q_{i}$. The equilibrium condition for the labor market in country $i$ thus reads $L_{i}^{x}+Q_{i}=1$. Inserting for $L_{i}^{x}$ in the first-order condition of firm $X$ 's profit maximization yields

$$
w_{i}=c+\delta F^{\prime}\left(1-Q_{i}\right)=: C\left(Q_{i}\right)
$$

Equation (6) gives the equilibrium wage rate in country $i$ as a function of the aggregate output in the $Y$-sector of this country. In the special case with $\delta=0$, the wage rate is fixed and, thus, $C^{\prime}=C^{\prime \prime}=0$. However, in our main case of interest with $\delta>0$ we obtain $C^{\prime}=-\delta F^{\prime \prime}>0$ and $C^{\prime \prime}=\delta F^{\prime \prime \prime} \geq 0$, i.e. the wage rate in country $i$ is increasing in aggregate output of sector $Y$ in country $i$ at non-decreasing rates. The reason is that a higher output in the $Y$-sector relocates labor from the numeraire good sector into sector $Y$ and thereby increases marginal productivity of labor in the numeraire good sector.

Polluting sector with exogenous location decision. The total number of firms in the $Y$-sector is $2 k$, while the number of firms located in the $Y$-sector of country $i$ is denoted by $k_{i}$, where $k_{i}+k_{j}=2 k$ with $i, j \in\{A, B\}$ and $i \neq j .{ }^{5}$ We first assume an exogenous and symmetric location of polluting firms with $k_{i}=k_{j}=k$. Firm $\ell$ in the $Y$-sector of country $i$ has an output of $q_{i \ell}$ units. We suppose a one-to-one relation between output and emissions generated in sector $Y$. Thus, $q_{i \ell}$ also measures the amount of emissions of firm $\ell$ in country $i$. The government of country $i$ taxes these emissions by the unit tax rate $\tau_{i}$. After-tax profits of firm $\ell$ in country $i$ can then be written as

$$
\pi_{i \ell}=\left[P\left(Q_{i,-\ell}+q_{i \ell}+Q_{j}\right)-C\left(Q_{i,-\ell}+q_{i \ell}\right)-\tau_{i}\right] q_{i \ell},
$$

where $Q_{i,-\ell}:=Q_{i}-q_{i \ell}$ is aggregate output of all other firms in sector $Y$ of country $i$. According to (7), profits equal revenues less labor costs and tax payments.

We assume that $k$ is small enough for the firms in the $Y$-sector to be imperfectly competitive à la Cournot-Nash on the input market and the output market. ${ }^{6}$ Formally, this implies that the $Y$-firms take into account their impact on the output price $P$ as well as on the wage rate $C$. While the impact on $P$ is standard in Cournot-Nash models, the impact on $C$ deserves some motivation. At first glance, an inconsistency is that on each

\footnotetext{
${ }^{5}$ For sake of convenience, we follow the procedure employed by, e.g., Requate (1997) and Haufler and Wooton (2010) and do not require $k_{i}$ to be an integer.

${ }^{6}$ Each firm may, e.g., possess sector-specific knowledge that allows this firm to produce the good. The knowledge is protected by patents, which creates a barrier to entry. See Haufler and Wooton (2010).
} 
local labor market firms from the $Y$-sector compete with firms from the $X$-sector, which are assumed to act under perfect competition on the labor market. This inconsistency is resolved, however, by implicitly assuming that the size of firms in the $Y$-sector is large relative to the aggregate (!) size of the firms in the $X$-sector. One general motivation for such an assumption may be the empirical finding of high levels of market concentrations in US labor markets (cf. Azar et al., 2017, 2018). More specific for our framework where in a later section we assume that $Y$-firms are internationally mobile, we may even refer to the strong empirical evidence that multinational enterprises have significant influence on local labor markets and wages. For instance, there is evidence for a multinational wage premium and wage spillovers to local establishments (cf. Aitken et al., 1996; Girma et al., 2001; Lipsey and Sjöholm, 2004; Tomohara and Takii, 2011).

Firm $\ell$ in the $Y$-sector of country $i$ maximizes (7) with respect to output $q_{i \ell}$, taking as given the output decision of all other firms in the $Y$-sector. Focusing on a symmetric equilibrium with $q_{i \ell}=q_{i}$ and $Q_{i}=k_{i} q_{i}$, the first-order condition reads

$$
P\left(k_{i} q_{i}+k_{j} q_{j}\right)+q_{i} P^{\prime}\left(k_{i} q_{i}+k_{j} q_{j}\right)-C\left(k_{i} q_{i}\right)-q_{i} C^{\prime}\left(k_{i} q_{i}\right)-\tau_{i}=0
$$

Equation (8) has the interpretation that an individual firm equates marginal revenues, $P+q_{i} P^{\prime}$, to marginal production costs, $C+q_{i} C^{\prime}$, plus the emissions tax rate, $\tau_{i}$. Due to our assumption that firms take into account their impact on the wage rate, the marginal production costs not only comprise the wage rate, $C$, but also the change in production costs via a change in the wage rate, i.e. $q_{i} C^{\prime}$.

Totally differentiating (8) and the corresponding equation for $Y$-firms in country $j$, taking into account $Q_{i}=k q_{i}$ and $Q_{j}=k q_{j}$ and evaluating the results at a symmetric situation with $q_{i}=q_{j}=: q$ and $Q_{i}=Q_{j}=: Q$, it is straightforward to prove

$$
\begin{gathered}
\left.\frac{\partial Q_{i}}{\partial \tau_{i}}\right|_{\mathrm{ex}}=\left.k \frac{\partial q_{i}}{\partial \tau_{i}}\right|_{\mathrm{ex}}=\frac{k \Gamma}{\Omega}<0,\left.\quad \frac{\partial Q_{j}}{\partial \tau_{i}}\right|_{\mathrm{ex}}=\left.k \frac{\partial q_{j}}{\partial \tau_{i}}\right|_{\mathrm{ex}}=-\frac{k^{2} \mathcal{X}}{\Omega}>0 \\
\left.\frac{\partial\left(Q_{i}+Q_{j}\right)}{\partial \tau_{i}}\right|_{\mathrm{ex}}=\frac{k\left(P^{\prime}-C^{\prime}-k \Psi\right)}{\Omega}<0
\end{gathered}
$$

where the subscript 'ex' indicates the case with an exogenously given location decision of firms and where, for notational convenience, we introduce

$$
\mathcal{X}:=P^{\prime}+q P^{\prime \prime}<0, \quad \Psi:=C^{\prime}+q C^{\prime \prime}>0
$$




$$
\Gamma:=k(\mathcal{X}-\Psi)+P^{\prime}-C^{\prime}<0, \quad \Omega:=\Gamma^{2}-k^{2} \mathcal{X}^{2}>0
$$

The sign of the Jacobian $\Omega$ follows from rewriting it as $\Omega=2 k \mathcal{X}\left(P^{\prime}-C^{\prime}-k \Psi\right)+\left(P^{\prime}-\right.$ $\left.C^{\prime}-k \Psi\right)^{2}>0$. The rationale of these insights is that the tax rate increase in country $i$ gives the polluting firms in the $Y$-sector of country $i$ a competitive disadvantage relative to their competitors in country $j$. Hence, the $Y$-firms in country $i$ produce and sell fewer units of good $Y$ and thereby reduce their emissions, whereas the $Y$-firms in country $j$ raise their output and emissions, as formally shown in equation (9). The latter effect is the leakage effect identified, e.g., in Felder and Rutherford (1993) and Babiker (2005) and empirically studied by Aichele and Felbermayr (2015). According to equation (10), leakage is incomplete in our model since aggregate output and emissions from both countries are lowered by the increase in the emissions tax rate in country $i$.

Polluting sector with endogenous location decision. Given the distribution of firms $\left(k_{i}, k_{j}\right)$, profit maximization again yields the first-order condition (8). In order to describe the firms' location decision, let $\pi_{i}$ and $\pi_{j}$ be the equilibrium profits of firms located in country $i$ and country $j$, respectively. Firms locate in the country where equilibrium profits are higher. If $\pi_{i}>\pi_{j}$, then firms move from country $j$ to country $i$, and vice versa. A location equilibrium is reached if profits in both countries are equalized. Using profits (7) and taking into account symmetry in each country, i.e. $q_{i \ell}=q_{i}$ and $q_{j \ell}=q_{j}$, the conditions of the location equilibrium can be written as

$$
\begin{gathered}
{\left[P\left(k_{i} q_{i}+k_{j} q_{j}\right)-C\left(k_{i} q_{i}\right)-\tau_{i}\right] q_{i}-\left[P\left(k_{i} q_{i}+k_{j} q_{j}\right)-C\left(k_{j} q_{j}\right)-\tau_{j}\right] q_{j}=0,} \\
k_{i}+k_{j}=2 k .
\end{gathered}
$$

Condition (11) equalizes equilibrium profits across countries, while condition (12) ensures that the number of firms located in the two countries is equal to the total number of firms. Note that an interior solution of the location equilibrium is ensured by our assumption of endogenous wage rates. If wage rates were fixed at $C(\cdot)=c$, we would obtain a bang-bang solution: For $\tau_{i}>\tau_{j}$, all firms would locate in country $j$, and vice versa. With endogenous wages, by contrast, the relocation of firms comes to a halt by adjustments of $C$.

Equations (11), (12) and (8) for $i$ and $j$ determine the firms' output, $q_{i}$ and $q_{j}$, and the firms' distribution, $k_{i}$ and $k_{j}$, as functions of the emissions tax rates, $\tau_{i}$ and $\tau_{j}$. Totally 
differentiating and evaluating the results at a symmetric situation with $q_{i}=q_{j}=: q$, $k_{i}=k_{j}=k$, and $\tau_{i}=\tau_{j}=: \tau$, the appendix derives the comparative static results

$$
\begin{aligned}
& \left.\frac{\partial q_{i}}{\partial \tau_{i}}\right|_{\text {en }}=\frac{\tilde{\pi} \Psi-q C^{\prime}\left(P^{\prime}-C^{\prime}\right)+q^{2} C^{\prime \prime}(\Gamma+k \mathcal{X})}{\tilde{\Omega}} \gtreqless 0, \\
& \left.\frac{\partial q_{j}}{\partial \tau_{i}}\right|_{\text {en }}=\frac{\tilde{\pi} \Psi-q C^{\prime}\left(P^{\prime}-C^{\prime}\right)-q^{2} C^{\prime \prime}(\Gamma+k \mathcal{X})}{\tilde{\Omega}}<0, \\
& \left.\frac{\partial k_{i}}{\partial \tau_{i}}\right|_{\text {en }}=-\left.\frac{\partial k_{j}}{\partial \tau_{i}}\right|_{\text {en }}=\frac{(\Gamma+k \mathcal{X})\left[-\tilde{\pi}+q\left(P^{\prime}-C^{\prime}\right)-q^{2} k C^{\prime \prime}\right]}{q \tilde{\Omega}}<0,
\end{aligned}
$$

where the subscript 'en' indicates the case of an endogenous location decision and where the equilibrium profit per unit of output and the Jacobian can be written as, respectively,

$$
\tilde{\pi}:=P-C-\tau \geq 0, \quad \tilde{\Omega}:=2(\Gamma+k \mathcal{X})\left[\tilde{\pi} \Psi-q C^{\prime}\left(P^{\prime}-C^{\prime}\right)\right]<0 .
$$

The rationale behind (13)-(15) is different from the case with exogenous location decision. The main channel of emissions leakage is now the relocation of firms. The increase in country $i$ 's tax rate reduces equilibrium profits of firms in country $i$ and, thus, gives firms an incentive to move to country $j$. The wage rate falls in country $i$ and increases in country $j$ until equilibrium profits are again equalized across countries. Hence, the number of firms falls in country $i$, while it increases in country $j$, as shown in (15). Since there are now more firms in country $j$, each of these firms produces less, according to (14). Similarly, the reduction of firms in country $i$ gives each firm in this country an incentive to increase output. However, since the tax rate has been increased in country $i$ there is a countervailing negative effect on output. The overall sign of the effect on the individual firm's output in country $i$ is therefore indeterminate, as can be seen in (13).

The effects of emission taxes on aggregate output and emissions in the two countries are obtained from $Q_{i}=k_{i} q_{i}$ and $Q_{j}=k_{j} q_{j}$. The appendix shows

$$
\begin{aligned}
\left.\frac{\partial Q_{i}}{\partial \tau_{i}}\right|_{\mathrm{en}} & =\frac{-\tilde{\pi}[\Gamma+k(\mathcal{X}-\Psi)]+q\left(P^{\prime}-C^{\prime}\right)\left[\Gamma+k \mathcal{X}-k C^{\prime}\right]}{\tilde{\Omega}}<0, \\
\left.\frac{\partial Q_{j}}{\partial \tau_{i}}\right|_{\mathrm{en}} & =\frac{\tilde{\pi}[\Gamma+k(\mathcal{X}+\Psi)]-q\left(P^{\prime}-C^{\prime}\right)\left[\Gamma+k \mathcal{X}+k C^{\prime}\right]}{\tilde{\Omega}}>0, \\
\left.\frac{\partial\left(Q_{i}+Q_{j}\right)}{\partial \tau_{i}}\right|_{\mathrm{en}} & =\frac{2 k\left[\tilde{\pi} \Psi-q C^{\prime}\left(P^{\prime}-C^{\prime}\right)\right]}{\tilde{\Omega}}=\frac{k\left(P^{\prime}-C^{\prime}-k \Psi\right)}{\Omega}<0,
\end{aligned}
$$


where the sign of (17) follows from $\Gamma+k(\mathcal{X}+\Psi)=2 k \mathcal{X}+P^{\prime}-C^{\prime}<0$ and $\Gamma+k \mathcal{X}+k C^{\prime}=$ $2 k \mathcal{X}+P^{\prime}-C^{\prime}-q k C^{\prime \prime}<0$. Equations (16)-(18) show that we obtain qualitatively the same results as in the case with exogenous location: An increase in country $i$ 's tax rate reduces total output and emissions in this country, see (16), while it increases total output and emissions in the other country, see (17). We obtain emissions leakage, which is again incomplete, since total emissions from both countries fall according to (18).

Comparison between exogenous and endogenous location decision. For the intuition of our main results derived below, it is important to compare the comparative static results in the cases of exogenous and endogenous location. In the appendix we show

$$
\begin{gathered}
\left.\frac{\partial Q_{i}}{\partial \tau_{i}}\right|_{\mathrm{en}}<\left.\frac{\partial Q_{i}}{\partial \tau_{i}}\right|_{\mathrm{ex}}<0,\left.\quad \frac{\partial Q_{j}}{\partial \tau_{i}}\right|_{\mathrm{en}}>\left.\frac{\partial Q_{j}}{\partial \tau_{i}}\right|_{\mathrm{ex}}>0, \\
\left.\frac{\partial\left(Q_{i}+Q_{j}\right)}{\partial \tau_{i}}\right|_{\mathrm{ex}}=\left.\frac{\partial\left(Q_{i}+Q_{j}\right)}{\partial \tau_{i}}\right|_{\mathrm{en}}<0 .
\end{gathered}
$$

According to (19), an increase in country $i$ 's tax rate leads to a larger decrease (increase) in country $i$ 's (country $j$ 's) output and emissions when firms are mobile instead of immobile. The gap between the decrease in country $i$ 's output and the increase in country $i$ 's output therefore becomes larger when we move from exogenous to endogenous location. The reason is that with mobile firms the increase in country $i$ 's tax rate not only impacts the output of firms, but it also lowers the number of firms in country $i$ for the benefit of country $j$. This relocation of firms amplifies both the fall in country $i$ 's total output and the increase in country $j$ 's total output. Interestingly, the larger decrease in country $i$ 's output and the larger increase in country $j$ 's output just offset each other. Accordingly, the effect of country $i$ 's tax rate on worldwide output and emissions is the same, regardless of whether the firms' location decision is exogenous or endogenous, as shown by (20).

\section{Strategic Environmental Policy}

Welfare function. Social welfare of country $i$ consists of consumption utility (1) less environmental damage. We model environmental damage in country $i$ by the function

$$
\varphi D\left(Q_{i}+\eta Q_{j}\right)
$$


with $\varphi \geq 0$ and $\eta \in[0,1]$ as well as $D^{\prime}>0, D^{\prime \prime} \geq 0$. The parameter $\varphi$ allows us to consider the case without environmental damage, i.e. the special case with $\varphi=0$. The parameter $\eta$ is introduced to differentiate between local and transboundary pollution. For $\eta=0$, emissions in country $i$ cause damage only in this country. For $\eta>0$, by contrast, we have emissions spillovers, so emissions in country $i$ also cause environmental damage in country $j$. The case of $\eta=1$ approximates the case of global warming; it is then irrelevant for the environmental damage in which country the emissions are generated.

Using (1), (2), and (21), welfare in country $i$ can be written as

$$
w_{i}+\Pi_{i}^{x}+\Pi_{i}+T^{i}-p y_{i}+Z\left(y_{i}\right)-\varphi D\left(Q_{i}+\eta Q_{j}\right)
$$

Inserting (6) and $L_{i}^{x}=1-Q_{i}$ into (5) gives profit income from the $X$-sector, i.e $\Pi_{i}^{x}=$ $\delta F\left(1-Q_{i}\right)+\left[c-C\left(Q_{i}\right)\right]\left(1-Q_{i}\right)$. Summing up (7) over all $k_{i}$ firms in country $i$ and using $Q_{i}=k_{i} q_{i}$ yields the profit income from the $Y$-sector equal to $\Pi_{i}=\left[P\left(Q_{i}+Q_{j}\right)-C\left(Q_{i}\right)-\right.$ $\left.\tau_{i}\right] Q_{i}$. Emissions tax revenues in country $i$ amount to $T_{i}=\tau_{i} Q_{i}$. The price $p$ and the wage rate $w_{i}$ can be replaced by (3) and (6), respectively. Finally, recall that $y_{i}=\left(Q_{i}+Q_{j}\right) / 2$. Inserting all this into (22) and canceling common terms gives

$$
\begin{aligned}
V\left(Q_{i}, Q_{j}\right):=c\left(1-Q_{i}\right)+\delta & F\left(1-Q_{i}\right)+Z\left(\frac{Q_{i}+Q_{j}}{2}\right) \\
+ & \frac{Q_{i}-Q_{j}}{2} Z^{\prime}\left(\frac{Q_{i}+Q_{j}}{2}\right)-\varphi D\left(Q_{i}+\eta Q_{j}\right) .
\end{aligned}
$$

Wage and tax payments of firms cancel out against wage and transfer income of the household. What remains in country $i$ 's welfare $(23)$ is the utility of good $X$, equal to the output of the $X$-sector, $c\left(1-Q_{i}\right)+\delta F\left(1-Q_{i}\right)$, the utility of good $Y$, represented by $Z\left[\left(Q_{i}+Q_{j}\right) / 2\right]$, environmental damage, equal to $-\varphi D\left(Q_{i}+\eta Q_{j}\right)$, and a term reflecting the success of the $Y$-sector in country $i$ relatively to the $Y$-sector in country $j$, measured by the value of country $i$ 's exports, $\left(Q_{i}-Q_{j}\right) Z^{\prime}\left[\left(Q_{i}+Q_{j}\right) / 2\right] / 2$. The value of exports stems from the difference of the $Y$-sectors' revenues $P\left(Q_{i}+Q_{j}\right) Q_{i}$ and the households' expenditures $P\left(Q_{i}+Q_{j}\right)\left(Q_{i}+Q_{j}\right) / 2$ (remember that $y_{i}=\left(Q_{i}+Q_{j}\right) / 2$ and $Z^{\prime}=P$ ). Country $i$ 's welfare (23) depends on the tax rates $\tau_{i}$ and $\tau_{j}$, since output volumes $Q_{i}$ and $Q_{j}$ depend on these tax rates according to our comparative static results derived above. 
Cooperative solution. As benchmark, we first derive the cooperative (efficient) emission tax rates which maximize joint welfare of both countries. Joint welfare equals

$$
\begin{aligned}
V\left(Q_{i}, Q_{j}\right)+V\left(Q_{j}, Q_{i}\right)= & c\left(1-Q_{i}\right)+\delta F\left(1-Q_{i}\right)+c\left(1-Q_{j}\right)+\delta F\left(1-Q_{j}\right) \\
& +2 Z\left(\frac{Q_{i}+Q_{j}}{2}\right)-\varphi D\left(Q_{i}+\eta Q_{j}\right)-\varphi D\left(Q_{j}+\eta Q_{i}\right)
\end{aligned}
$$

It encompasses utility of good $X$ and good $Y$ and environmental damage in both countries. In contrast to the individual country's welfare (23), the value of exports does not play a role in joint welfare, since the countries' values of exports cancel out.

As both countries are structurally identical, we focus on the symmetric solution $\tau_{i}=\tau^{*}$ of joint welfare maximization. For equal tax rates, also the output and emission levels are equal and denoted by $Q_{i}=Q^{*}$. We furthermore obtain $F^{\prime}\left(1-Q_{i}\right)=F^{\prime}\left(1-Q^{*}\right)$ and $D\left[Q_{i}+\eta Q_{j}\right]=D\left[(1+\eta) Q^{*}\right]$. Setting the derivative of $(24)$ with respect to $\tau_{i}$ equal to zero, applying the symmetry property and taking into account that $\partial\left(Q_{i}+Q_{j}\right) / \partial \tau_{i}<0$ due to (10) or (18), we obtain the first-order condition for the cooperative solution

$$
Z^{\prime}\left(Q^{*}\right)=c+\delta F^{\prime}\left(1-Q^{*}\right)+\varphi(1+\eta) D^{\prime}\left[(1+\eta) Q^{*}\right]
$$

To understand the intuition of this efficiency condition, remember from the previous section that an increase in country $i$ 's tax rate reduces output of the $Y$-sector in country $i$ and increases output of the $Y$-sector in country $j$. Total output of the $Y$-sector and, thus, consumption of good $Y$ in both countries fall. Via local labor markets, output of the $X$-sector increases in country $i$ and decreases in country $j$. Pollution in country $i$ decreases since leakage is incomplete, while pollution in country $j$ may increase or decrease depending on the spillover parameter $\eta$. In country $i$, these changes lead to a reduction in utility of good $Y$, represented by $\frac{1}{2} Z^{\prime}(\cdot)\left(\partial Q_{i} / \partial \tau_{i}+\partial Q_{j} / \partial \tau_{i}\right)<0$, an increase in utility of good $X$, given by $-\left[c+\delta F^{\prime}(\cdot)\right] \partial Q_{i} / \partial \tau_{i}>0$, and a fall in environmental damage, reflected by $-\varphi D^{\prime}(\cdot)\left(\partial Q_{i} / \partial \tau_{i}+\eta \partial Q_{j} / \partial \tau_{i}\right)>0$. In country $j$, we obtain a reduction in utility of good $Y$, represented by $\frac{1}{2} Z^{\prime}(\cdot)\left(\partial Q_{j} / \partial \tau_{i}+\partial Q_{i} / \partial \tau_{i}\right)<0$, a decrease in utility of good $X$, given by $-\left[c+\delta F^{\prime}(\cdot)\right] \partial Q_{j} / \partial \tau_{i}<0$, and a change in environmental damage, reflected by $-\varphi D^{\prime}(\cdot)\left(\partial Q_{j} / \partial \tau_{i}+\eta \partial Q_{i} / \partial \tau_{i}\right) \gtreqless 0$. The cooperative tax rate equalizes the sum of all these marginal welfare effects to zero. Due to symmetry, the terms $Z^{\prime}, c+\delta F^{\prime}$ and $\varphi D^{\prime}$ are the same in both countries. We may thus factor out the change in total output $\partial\left(Q_{i}+Q_{j}\right) / \partial \tau_{i}$ and arrive at (25). Intuitively, this equation states that for good $Y$ the 
marginal utility $Z^{\prime}$ is equal to the opportunity costs $c+\delta F^{\prime}$, representing marginal output and utility of good $X$, plus the marginal environmental damage $\varphi(1+\eta) D^{\prime}$. With $Z^{\prime}=P$ and $c+\delta F^{\prime}=C$ from (3) and (6), we obtain the alternative interpretation that the efficient emission tax rate equates the price of $\operatorname{good} Y$, on the one hand, and the marginal production and environmental costs of good $Y$, on the other hand.

Using (25) together with $Z^{\prime}=P$ and $c+\delta F^{\prime}=C$ from (3) and (6) in (8), we obtain

$$
\tau^{*}=\varphi(1+\eta) D^{\prime}\left[(1+\eta) Q^{*}\right]+\frac{Q^{*}}{k} P^{\prime}\left(2 Q^{*}\right)-\frac{Q^{*}}{k} C^{\prime}\left(Q^{*}\right)
$$

This expressions gives the efficient emissions tax rate which equals the marginal environmental damage, $\varphi(1+\eta) D^{\prime}$, corrected by terms reflecting the market power of firms in the $Y$-sector on the output market, $Q^{*} P^{\prime} / k$, and on the input market, $Q^{*} C^{\prime} / k$. Hence, efficiency requires underinternalization of the marginal damage, $\varphi(1+\eta) D^{\prime}$, since the efficient emissions tax rate not only has to internalize the environmental externality by imposing a tax, but also the market power of firms by granting a subsidy. ${ }^{7}$

Non-cooperative solution with exogenous location decision. Non-cooperation is modeled as a Nash policy game where country $i$ chooses $\tau_{i}$ in order to maximize own welfare (23), taking into account the comparative static effects derived in the previous section and taking as given the choice of the tax rate $\tau_{j}$ by country $j$. We first focus on a fixed firm distribution with $k_{i}=k_{j}=k$. Symmetry now implies $\tau_{i}=: \tau^{\mathrm{ex}}, Q_{i}=: Q^{\mathrm{ex}}$, $F^{\prime}\left(1-Q_{i}\right)=F^{\prime}\left(1-Q^{\mathrm{ex}}\right)$, and $D\left[Q_{i}+\eta Q_{j}\right]=D\left[(1+\eta) Q^{\mathrm{ex}}\right]$. Differentiating (23) with respect to $\tau_{i}$ and applying symmetry afterwards, the Nash equilibrium condition becomes

$$
Z^{\prime}\left(Q^{\mathrm{ex}}\right)=c+\delta F^{\prime}\left(1-Q^{\mathrm{ex}}\right)+\varphi D^{\prime}\left[(1+\eta) Q^{\mathrm{ex}}\right]\left(1+\left.\eta \frac{\partial Q_{j}}{\partial \tau_{i}}\right|_{\mathrm{ex}} /\left.\frac{\partial Q_{i}}{\partial \tau_{i}}\right|_{\mathrm{ex}}\right)
$$

Using (27), $Z^{\prime}=P$ and $c+\delta F^{\prime}=C$ in (8) yields for the equilibrium tax rate

$$
\tau^{\mathrm{ex}}=\varphi D^{\prime}\left[(1+\eta) Q^{\mathrm{ex}}\right]\left(1+\left.\eta \frac{\partial Q_{j}}{\partial \tau_{i}}\right|_{\mathrm{ex}} /\left.\frac{\partial Q_{i}}{\partial \tau_{i}}\right|_{\mathrm{ex}}\right)+\frac{Q^{\mathrm{ex}}}{k} P^{\prime}\left(2 Q^{\mathrm{ex}}\right)-\frac{Q^{\mathrm{ex}}}{k} C^{\prime}\left(Q^{\mathrm{ex}}\right)
$$

Comparing the non-cooperative Nash equilibrium described by (27) and (28) with the efficient policy in (25) and (26), the appendix proves

\footnotetext{
${ }^{7}$ This argument was first put forward by Buchanan (1969) and Barnett (1980) for the case of a monopoly and Ebert (1992) for oligopolistic market structures.
} 
Proposition 1. (i) If $\varphi=0$ or $\eta=0$, then $\tau^{e x}=\tau^{*}$ and $Q^{e x}=Q^{*}$. (ii) If $\varphi>0$ and $\eta>0$, then $\tau^{e x}<\tau^{*}$ and $Q^{e x}>Q^{*}$.

According to part (i) of Proposition 1, the non-cooperative policy choice may be efficient. This is the case if there is no environmental externality at all $(\varphi=0)$ or if emissions do not cause cross-border spillovers $(\eta=0)$. In the absence of environmental damage $(\varphi=0)$, the efficient tax rate (26) and the Nash equilibrium tax rate (28) are equal to $\tau^{*}=\tau^{\mathrm{ex}}=$ $Q^{\operatorname{ex}}\left(P^{\prime}-C^{\prime}\right) / k<0$ and represent a subsidy which corrects for imperfect competition in the input and output markets of sector $Y$. In the case of local pollution $(\varphi>0$ and $\eta=0$ ), the two tax rates additionally reflect the marginal environmental damage and may thus become positive and reflect a tax instead of a subsidy. Only with environmental externality and cross-border spillovers $(\varphi>0$ and $\eta>0)$, the non-cooperative policy deviates from the efficient one. In this case, the non-cooperative emissions tax rate is inefficiently low $\left(\tau^{\mathrm{ex}}<\tau^{*}\right)$, implying an inefficiently high output and inefficiently high emissions under non-cooperation $\left(Q^{\mathrm{ex}}>Q^{*}\right)$, as shown in part (ii) of Proposition 1.

At first glance, one may conjecture that the efficiency result in part (i) of Proposition 1 is obtained because without environmental pollution $(\varphi=0)$ or emissions spillovers $(\eta=$ $0)$, there are no cross-border effects between the two countries. But the rationale is more complicated than this. Even for $\varphi=0$ or $\eta=0$, a tax rate change in one country has an effect on firms and households in the other country via changes in output in the other country, as shown by the comparative static result (9) which is independent of $\varphi$ and $\eta$. Hence, the efficiency result comes as surprise. In order to resolve this puzzle, we take a look at the policy externality, i.e. the effect of country $i$ 's emissions tax rate on welfare in country $j$. This effect is ignored by country $i$ in setting its tax rate non-cooperatively and, thus, it explains the difference between the Nash policy equilibrium and the efficient solution. Formally, differentiating (23) yields the policy externality

$$
\frac{\partial V\left(Q_{j}, Q_{i}\right)}{\partial \tau_{i}}=\mathrm{CE}+\mathrm{PE}
$$

with

$$
\begin{aligned}
\mathrm{CE} & =\left.\left[Z^{\prime}\left(Q^{\mathrm{ex}}\right)-c-\delta F^{\prime}\left(1-Q^{\mathrm{ex}}\right)\right] \frac{\partial Q_{j}}{\partial \tau_{i}}\right|_{\mathrm{ex}}, \\
\mathrm{PE} & =-\varphi D^{\prime}\left[(1+\eta) Q^{\mathrm{ex}}\right]\left(\left.\frac{\partial Q_{j}}{\partial \tau_{i}}\right|_{\mathrm{ex}}+\left.\eta \frac{\partial Q_{i}}{\partial \tau_{i}}\right|_{\mathrm{ex}}\right) .
\end{aligned}
$$


The total externality can be decomposed into a consumption externality CE and a pollution externality PE. The consumption externality CE reflects the change in country $j$ 's welfare due to the fall in utility of good $Y$ given by $\left.\frac{1}{2} Z^{\prime}(\cdot)\left(\partial Q_{j} / \partial \tau_{i}+\partial Q_{i} / \partial \tau_{i}\right)\right|_{\text {ex }}<0$, the decrease in utility of good $X$ equal to $-\left.\left[c+\delta F^{\prime}(\cdot)\right]\left(\partial Q_{j} / \partial \tau_{i}\right)\right|_{\text {ex }}<0$ and the increase in the value of exports reflected by $\left.\frac{1}{2} Z^{\prime}(\cdot)\left(\partial Q_{j} / \partial \tau_{i}-\partial Q_{i} / \partial \tau_{i}\right)\right|_{\mathrm{ex}}>0$. The pollution externality $\mathrm{PE}$ equals the change in damage given by $-\left.\varphi D^{\prime}(\cdot)\left(\partial Q_{j} / \partial \tau_{i}+\eta \partial Q_{i} / \partial \tau_{i}\right)\right|_{\mathrm{ex}} \gtreqless 0$.

In the absence of environmental damage $(\varphi=0)$, it is obvious that the pollution externality is zero $(\mathrm{PE}=0)$. Moreover, the Nash equilibrium condition (27) becomes $Z^{\prime}=c+\delta F^{\prime}$, implying that the welfare effects on utility of good $Y$, utility of good $X$ and exports in country $j$ just offset each other and drive down the consumption externality in $(30)$ to zero $(\mathrm{CE}=0)$. Hence, in the absence of environmental pollution, the tax rate in the non-cooperative Nash equilibrium is efficient since both subexternalities, CE and PE, and thereby the total policy externality in (29) are indeed zero. But in case of local pollution $(\varphi>0, \eta=0)$, the pollution externality is strictly negative $\left(\mathrm{PE}=-\left.\varphi D^{\prime}(\cdot)\left(\partial Q_{j} / \partial \tau_{i}\right)\right|_{\mathrm{ex}}<\right.$ $0)$, since due to emission leakage a tax rate increase in country $i$ increases emissions and, thus, damage in country $j$, even in the absence of emission spillovers. Moreover, the Nash equilibrium condition (27) now implies $Z^{\prime}=c+\delta F^{\prime}+\varphi D^{\prime}$. Inserting this into (30) yields $\mathrm{CE}=-\mathrm{PE}$. Hence, in case of local pollution the non-cooperative tax rates become efficient not because there are no cross-country effects of tax policy, as conjectured at first glance, but since the two subexternalities CE and PE just offset each other.

In order to explain part (ii) of Proposition 1, note that for global pollution $(\varphi>$ $0, \eta>0)$ the sign of both subexternalities (30) and (31) is indeterminate, in general. However, taking into account the Nash equilibrium condition (27) in order to replace $Z^{\prime}-c-\delta F^{\prime}$ in CE defined in (30), we can show after some rearrangements that

$$
\mathrm{CE}+\mathrm{PE}=-\eta \varphi D^{\prime}\left[(1+\eta) Q^{\mathrm{ex}}\right]\left[\left(\left.\frac{\partial Q_{j}}{\partial \tau_{i}}\right|_{\mathrm{ex}}\right)^{2}-\left(\left.\frac{\partial Q_{i}}{\partial \tau_{i}}\right|_{\mathrm{ex}}\right)^{2}\right] /\left.\frac{\partial Q_{i}}{\partial \tau_{i}}\right|_{\mathrm{ex}}>0
$$

The sign of equation (32) follows from the fact that leakage is incomplete, i.e. $\left.\left(\partial Q_{j} / \partial \tau_{i}\right)\right|_{\text {ex }}<$ $-\left.\left(\partial Q_{i} / \partial \tau_{i}\right)\right|_{\text {ex }}$ due to $(10)$. Hence, the sum of the two subexternalities is positive and in the Nash equilibrium the non-cooperative emissions tax rate is inefficiently low.

Non-cooperative solution with endogenous location decision. If the location decision of firms is endogenous, we obtain the same Nash equilibrium condition as in 
(27), the same equilibrium emissions tax rate as in (28) and the same policy externalities as in (29)-(31), except that we have to replace $Q^{\mathrm{ex}}$ by $Q^{\mathrm{en}}$ and the comparative static effects (9) and (10) by (16)-(18). Based on these changes, the appendix proves

Proposition 2. (i) If $\varphi=0$ or $\eta=0$, then $\tau^{e n}=\tau^{e x}=\tau^{*}$ and $Q^{e n}=Q^{e x}=Q^{*}$. (ii) If $\varphi>0$ and $\eta>0$, then $\tau^{e n}<\tau^{e x}<\tau^{*}$ and $Q^{e n}>Q^{e x}>Q^{*}$.

According to part (i) of Proposition 2, without environmental damage $(\varphi=0)$ or with local pollution $(\varphi>0, \eta=0)$, the non-cooperative Nash equilibrium with an endogenous location decision of firms is efficient, as in the case with an exogenous location decision. By contrast, with global environmental pollution $(\varphi>0, \eta>0)$, the inefficiency of the non-cooperative Nash emissions tax rates is aggravated when we move from an exogenous to an endogenous location decision, as shown in part (ii) of Proposition 2.

The rationale of these insights goes again back to the externalities in (29)-(31), now with the comparative static effects in (16)-(18) instead of (9) and (10). Without environmental damage $(\varphi=0)$, both the consumption externality CE in (30) and the pollution externality PE in (31) are again zero, implying an efficient policy choice in the Nash equilibrium, as shown in part (i) of Proposition 2. In the presence of an environmental externality $(\varphi>0)$, both subexternalities are non-zero and larger in absolute terms than in the case of an exogenous location decision, since from (19) we know that leakage is larger if firms in the $Y$-sector are mobile instead of immobile. In case of local pollution $(\varphi>0$ and $\eta=0)$, however, both $\mathrm{CE}$ and $\mathrm{PE}$ are aggravated to the same extent, so the sum of both remains zero and the equilibrium tax rates are again efficient, as stated in part (i) of Proposition 2. If pollution is global $(\varphi>0$ and $\eta>0)$, by contrast, equation (32) shows that the larger spread between CE and PE under firm mobility increases the inefficiency of the equilibrium tax rate as well as the equilibrium output and emissions compared to the case with immobile firm, as shown in part (ii) of Proposition 2.

\section{Discussion}

Comparison to autarky. In our model, autarky means that firms are immobile and there is trade neither in good $X$ nor good $Y$. The analysis of the $X$-sector remains unchanged in this case, leading again to (6). The household's demand decision in country $i$ again implies $p=Z^{\prime}\left(y_{i}\right)$. Since there is no trade in good $Y$, however, market clearing 
now gives $y_{i}=Q_{i}$ and the demand function becomes $p=Z^{\prime}\left(Q_{i}\right)=: \widetilde{P}\left(Q_{i}\right)$. In an online appendix we show that the effect of country $i$ 's tax rate on output in country $i$ is still negative, i.e. $\left.\left(\partial Q_{i} / \partial \tau_{i}\right)\right|_{\text {aut }}<0$, and that the effect of country $i$ 's tax rate on output in country $j$ vanishes, i.e. $\left.\left(\partial Q_{j} / \partial \tau_{i}\right)\right|_{\text {aut }}=0$, where the index 'aut' indicates the non-cooperative solution under autarky. Welfare of country $i$ turns into

$$
\widetilde{V}\left(Q_{i}, Q_{j}\right):=c\left(1-Q_{i}\right)+\delta F\left(1-Q_{i}\right)+Z\left(Q_{i}\right)-\varphi D\left(Q_{i}+\eta Q_{j}\right) .
$$

Maximizing $\widetilde{V}\left(Q_{i}, Q_{j}\right)+\widetilde{V}\left(Q_{j}, Q_{i}\right)$ yields the same efficiency condition (25) as under free trade. By contrast, from (33) the non-cooperative Nash equilibrium condition becomes

$$
Z^{\prime}\left(Q^{\text {aut }}\right)=c+\delta F^{\prime}\left(1-Q^{\text {aut }}\right)+\varphi D\left[(1+\eta) Q^{\text {aut }}\right]
$$

Comparing (25) and (34), we see that the only cross-country effect which country $i$ does not take into account in its non-cooperative policy choice under autarky is the emission spill-over of its output $Q_{i}$. In terms of externalities, we obtain a positive pollution externality equal to $\widetilde{\mathrm{PE}}=-\left.\eta \varphi D^{\prime}\left[(1+\eta) Q^{\text {aut }}\right]\left(\partial Q_{i} / \partial \tau_{i}\right)\right|_{\text {aut }}>0$. Hence, also under autarky the non-cooperative tax rate $\tau^{\text {aut }}$ is inefficiently low. Moreover, in the online appendix we show that the policy externality is smaller, and the emissions tax rate thereby larger, under autarky than under free trade. This implies that we can decompose the inefficiency of the non-cooperative emissions policy into three parts: inefficiency due to free-riding $\left(\tau^{*}>\tau^{\text {aut }}\right)$, strategic incentives $\left(\tau^{\text {aut }}>\tau^{\mathrm{ex}}\right)$, and firm mobility $\left(\tau^{\mathrm{ex}}>\tau^{\mathrm{en}}\right)$.

The role of endogenous wage rates. Beside ensuring an interior location equilibrium in the presence of mobile firms, the endogeneity of wage rates also has an impact on the degree of inefficiency of the non-cooperative policy equilibrium. In order to illustrate, we focus on the case with immobile firms and compare model results with endogenous wage rates, i.e. $\delta>0$ and $C\left(Q_{i}\right)=c+\delta F^{\prime}\left(1-Q_{i}\right)$, to outcomes with exogenous wage rates, i.e. $\delta=0$ and $C\left(Q_{i}\right)=c$. Unfortunately, this analysis is not tractable in the case of general functional forms of $Z$ and $F$. However, in an online appendix we show that moving from exogenous to endogenous wage rates reduces the gap between the efficient solution and the non-cooperative Nash equilibrium, if $Z$ and $F$ are quadratic and thereby $P$ and $C$ are linear. The rationale of this insight is as follows: Suppose country $i$ decreases its tax rate. The corresponding increase in the domestic firms' output is determined by the reduction in the after-tax marginal production costs. This reduction is smaller under endogenous 
than under exogenous wage rates since in the former case domestic marginal labor costs increase due to the higher output and counteract the fall in the tax rate. At the same time, the increase of domestic firms' output induces the foreign firms in sector $Y$ to cut back their production causing a reduction in the foreign wage rate. This attenuates the rise in the domestic firms' competitiveness further. Hence, with endogenous wages, the government can to a smaller extent use a tax reduction to improve the market position and, hence, increase the profits of its domestic firms. Accordingly, the deviation of noncooperative tax setting from the first-best is less pronounced, when taking into account the general equilibrium effect of endogenous wages.

The role of imperfect competition. In order to highlight the role of imperfect competition, consider perfectly competitive firms in the $Y$-sector. Instead of (8), profit maximization in the $Y$-sector then yields $P\left(Q_{i}+Q_{j}\right)-C\left(Q_{i}\right)-\tau_{i}=0$ and $P\left(Q_{i}+Q_{j}\right)-C\left(Q_{j}\right)-$ $\tau_{j}=0$. Inserting into (11) and (12), we see that the condition of the location equilibrium is always fulfilled and any firm distribution constitutes an equilibrium. Focusing on the symmetric distribution with $k_{i}=k_{j}=k$, it is then obvious that the cases of exogenous and endogenous firm location are identical. Therefore, under perfect competition the non-cooperative policy is always independent of whether firms are mobile or immobile $\left(\tau^{\mathrm{ex}}=\tau^{\mathrm{en}}\right.$ and $\left.Q^{\mathrm{ex}}=Q^{\mathrm{en}}\right)$. Put differently, imperfect competition is the reason why mobility of firms renders the non-cooperative policy even more inefficient. The intuition is that with perfect competition, all $Y$-firms have zero profits and, thus, no government can provide firms tax incentives to relocate, in contrast to imperfect competition.

Note, however, that for $\varphi>0$ and $\eta>0$ the non-cooperative solution remains inefficient under perfect competition. Differentiating the above first-order conditions yields

$$
\left.\frac{\partial Q_{i}}{\partial \tau_{i}}\right|_{\mathrm{ex}}=\left.\frac{\partial Q_{i}}{\partial \tau_{i}}\right|_{\mathrm{en}}=\frac{P^{\prime}-C^{\prime}}{C^{\prime}\left(C^{\prime}-2 P^{\prime}\right)}<0,\left.\quad \frac{\partial Q_{j}}{\partial \tau_{i}}\right|_{\mathrm{ex}}=\left.\frac{\partial Q_{j}}{\partial \tau_{i}}\right|_{\mathrm{en}}=\frac{-P^{\prime}}{C^{\prime}\left(C^{\prime}-2 P^{\prime}\right)}>0 .
$$

Conditions (25) and (27) for the cooperative and non-cooperative policy, respectively, remain unchanged. Due to the signs in (35), we can use the same steps as in the proof of Propositions 1 and 2 in order to show $\tau^{\mathrm{ex}}=\tau^{\mathrm{en}}<\tau^{*}$ and $Q^{\mathrm{ex}}=Q^{\mathrm{en}}>Q^{*}$ if $\varphi>0$ and $\eta>0$. Hence, also under perfect competition non-cooperation yields inefficiently low emission taxes and inefficiently high emission levels. Intuitively, even under perfect competition emission leakage is incomplete since (35) implies $\left.\left[\partial\left(Q_{i}+Q_{j}\right) / \partial \tau_{i}\right]\right|_{\mathrm{ex}}=$ 
$-1 /\left(C^{\prime}-2 P^{\prime}\right)<0$. The sum of the consumption externality $\mathrm{CE}$ and the pollution externalities PE in (32) therefore remains positive, explaining inefficient undertaxation.

The role of the integrated market. To explain the difference between our efficiency result in the absence of pollution and the inefficiency result derived by the literature on strategic trade policy, we set $\varphi=0$ and deviate from our integrated market assumption. Instead, we follow a large part of the strategic trade policy literature (Brander, 1995) and consider a model version with a third country $C$. Only country $C$ consumes good $Y$, whereas this good is produced solely in the other two countries. We focus on the case with an exogenous location decision. The case with firm mobility is analogous.

In country $C$, all labor is used in the numeraire sector, so the wage rate becomes $w_{C}=$ $c+\delta F^{\prime}(1)$ and profits read $\Pi_{C}^{x}=\delta\left[F(1)-F^{\prime}(1)\right]$. The household has utility $Z\left(y_{C}\right)+x_{C}$, and the budget is $x_{C}+p y_{C}=m$ with the fixed income $m:=w_{C}+\Pi_{C}^{x}=c+\delta F(1)$. Demand for good $Y$ satisfies the first-order condition $p=Z^{\prime}\left(y_{C}\right)$. The market clearing condition for good $Y$ is $y_{C}=Q_{i}+Q_{j}$, so the demand function reads $p=Z^{\prime}\left(Q_{i}+Q_{j}\right)=: \widehat{P}\left(Q_{i}+Q_{j}\right)$. Welfare in country $C$ can therefore be computed as

$$
\widehat{V}^{C}\left(Q_{i}, Q_{j}\right):=m+Z\left(Q_{i}+Q_{j}\right)-\left(Q_{i}+Q_{j}\right) Z^{\prime}\left(Q_{i}+Q_{j}\right) .
$$

It equals the fixed income plus utility less payments for good $Y\left(\right.$ remember $Z^{\prime}=P$ ). In country $i \in\{A, B\}$, both production sectors remain unchanged, except for the change in the demand function for good $Y$. Hence, we again obtain (4)-(10), but now with $\widehat{P}, \widehat{P}^{\prime}$ and $\widehat{P}^{\prime \prime}$ instead of $P, P^{\prime}$ and $P^{\prime \prime}$, respectively. Utility $Z\left(y_{i}\right)$ and expenditures $p y_{i}$ vanish from welfare (22). Taking into account $\varphi=0$, instead of (23) we obtain

$$
\widehat{V}\left(Q_{i}, Q_{j}\right):=c\left(1-Q_{i}\right)+\delta F\left(1-Q_{i}\right)+Q_{i} Z^{\prime}\left(Q_{i}+Q_{j}\right) .
$$

The term $Q_{i} Z^{\prime}(\cdot)$ is the value of country $i$ 's exports of good $Y$ to the third country. Accordingly, in joint welfare $\widehat{V}\left(Q_{i}, Q_{j}\right)+\widehat{V}\left(Q_{j}, Q_{i}\right)$ we obtain the term $\left(Q_{i}+Q_{j}\right) Z^{\prime}(\cdot)$ which represents exports of both countries to the third country.

The cooperative solution between all three countries maximizes $\widehat{V}^{C}\left(Q_{i}, Q_{j}\right)+\widehat{V}\left(Q_{i}, Q_{j}\right)+$ $\widehat{V}\left(Q_{j}, Q_{i}\right)$. Differentiating gives the first-order condition

$$
Z^{\prime}\left(2 \widehat{Q}^{*}\right)=c+\delta F^{\prime}\left(1-\widehat{Q}^{*}\right)
$$


which has the same interpretation as (25) for $\varphi=0$. The partial cooperative policy between $A$ and $B$ maximizes $\widehat{V}\left(Q_{i}, Q_{j}\right)+\widehat{V}\left(Q_{j}, Q_{i}\right)$ and satisfies

$$
Z^{\prime}\left(2 \widehat{Q}^{* *}\right)=c+\delta F^{\prime}\left(1-\widehat{Q}^{* *}\right)-2 \widehat{Q}^{* *} Z^{\prime \prime}\left(2 \widehat{Q}^{* *}\right)
$$

From the point of view of the two producing countries, $Z^{\prime}$ on the LHS can be interpreted as a marginal costs of a tax rate increase, since the higher tax reduces total output $Q_{i}+Q_{j}$ and, for constant price $P=Z^{\prime}$, export revenues. The RHS gives the producing countries' marginal benefits of a tax rate increase, consisting of the higher output in the numeraire sector, $c+\delta F^{\prime}$, and an increase in the export value due to a price increase, $-2 Q^{* *} Z^{\prime \prime}$, for constant output. Hence, partial cooperation ignores the corresponding increase in country $C$ 's import expenditures, amounting to a negative import externality inflicted on country $C$. The non-cooperative solution maximizes (37) and satisfies

$$
Z^{\prime}\left(2 \widehat{Q}^{\mathrm{ex}}\right)=c+\delta F^{\prime}\left(1-\widehat{Q}^{\mathrm{ex}}\right)-\widehat{Q}^{\mathrm{ex}} Z^{\prime \prime}\left(2 \widehat{Q}^{\mathrm{ex}}\right)\left(\left.\frac{\partial Q_{i}}{\partial \tau_{i}}\right|_{\widehat{\mathrm{ex}}}+\left.\frac{\partial Q_{j}}{\partial \tau_{i}}\right|_{\widehat{\mathrm{ex}}}\right) /\left.\frac{\partial Q_{i}}{\partial \tau_{i}}\right|_{\widehat{\mathrm{ex}}}
$$

In contrast to partial cooperation, country $i$ now not only ignores the negative effect of its tax rate increase on the imports of the third country, but also the positive effect on country $j$ 's value of exports, caused by an increase in output $Q_{j}$, for constant export price, and an increase in the export price $P=Z^{\prime}$, for constant output. This constitutes a positive export externality on country $j$, reflected by the last term on the RHS of (40).

Based on these insights, we prove in an online appendix that the non-cooperative tax rate is smaller, and output larger, than under partial cooperation. This result is caused by the positive export externality and coincides with the inefficiency result derived in the strategic trade policy literature, see e.g. Brander (1995). ${ }^{8}$ If we compare non-cooperative taxes with full cooperation, the negative import externality comes into play. This externality overcompensates the positive export externality, since trade balance implies that changes in export and import values are equal in absolute terms and since country $i$ takes into account a part of the change in the export value, namely the effect on its own exports. Hence, the sum of the import and export externalities is negative, implying that tax rates are higher (subsidies lower) under non-cooperation than under full cooperation.

\footnotetext{
${ }^{8}$ To avoid clutter in notation, we have stuck here to the analysis of taxes instead of subsidies. Both approaches are equivalent, however, if we replace the tax by a subsidy $\sigma_{i}:=-\tau_{i}$. Our analysis then implies that the non-cooperative subsidy is higher than under partial cooperation, as in Brander (1995).
} 


\section{Conclusion}

This paper revisits the literature on strategic environmental policy by integrating two aspects into the general framework. First, we add firm mobility directly to the analysis. This allows us to compare policy effects on the intensive and extensive margins. Moreover, we can highlight when and how the mobility of polluting firms amplifies the deviation of the non-cooperative policy setting from the welfare-maximizing outcome. Second, we endogenize the production costs of polluting firms by using a general equilibrium approach including the labor market. Wage responses to output and location changes of mobile firms ensure an interior solution of the location equilibrium. Moreover, we show how this general equilibrium effect countervails strategic motives of non-cooperatively acting policy-makers and reduces the inefficiency of decentralized policy.

Our main results show that decentralized policy-setting with mobile firms does not necessarily lead to inefficient outcomes. This efficiency result is obtained in the case of only local pollution, and in the absence of any environmental damage. By contrast, with transboundary pollution, non-cooperative policy-setting is inefficient, and the mobility of polluting firms aggravates the inefficiency. By additionally considering the benchmark of an autarky economy, we show that the inefficiency of non-cooperative tax rates can be decomposed in a first part caused by the standard free-riding incentives in decentralized environmental policy, a second part implied by the strategic incentives of governments to promote the firms located in their countries, and a third part generated by firm mobility.

The game-theoretic literature on climate policy (e.g., Barrett 1994) helps to explain why many countries do not regulate their emissions of greenhouse gases in a way compatible with, e.g., the 2-degree Celsius target: free-riding prevents them from internalizing environmental externalities on other countries, and cooperation is hard to achieve. Yet, this does not explain why so many countries until today fail to implement any carbon price at all. If free-riding were the only problem, countries should nevertheless implement positive carbon prices to regulate those externalities that accrue within their own boundaries. Our analysis points towards competitiveness concerns as another reason (in addition to free-riding) why countries may shy away from regulating their emissions unilaterally. Interestingly, Helm and Schmidt (2015) show that border carbon adjustment (BCA) can help to address the free-rider problem, thereby triggering higher participation in a climate change agreement. Hence, our analysis raises the question whether BCA 
can also mitigate the flaws caused by competitiveness considerations in unilateral climate policy. The corresponding analysis of BCA in the context of our modeling framework goes beyond the scope of this paper, but might be a good starting point for future research.

\section{Appendix}

Proof of (13)-(18). Let $\hat{q}_{i}:=\left.\left(\partial q_{i} / \partial \tau_{i}\right)\right|_{\mathrm{en}}, \hat{k}_{i}:=\left.\left(\partial k_{i} / \partial \tau_{i}\right)\right|_{\mathrm{en}}, \hat{Q}_{i}:=\left.\left(\partial Q_{i} / \partial \tau_{i}\right)\right|_{\mathrm{en}}$, $\hat{q}_{j}:=\left.\left(\partial q_{j} / \partial \tau_{i}\right)\right|_{\mathrm{en}}, \hat{k}_{j}:=\left.\left(\partial k_{j} / \partial \tau_{i}\right)\right|_{\mathrm{en}}, \hat{Q}_{j}:=\left.\left(\partial Q_{j} / \partial \tau_{i}\right)\right|_{\mathrm{en}}, \hat{q}:=\left.\left[\partial\left(q_{i}+q_{j}\right) / \partial \tau_{i}\right]\right|_{\mathrm{en}}$ and $\hat{Q}:=\left.\left[\partial\left(Q_{i}+Q_{j}\right) / \partial \tau_{i}\right]\right|_{\text {en }}$. In a symmetric situation we have $\hat{q}=\hat{q}_{i}+\hat{q}_{j}, \hat{Q}_{i}=q \hat{k}_{i}+k \hat{q}_{i}$ and $\hat{Q}=\hat{Q}_{i}+\hat{Q}_{j}=k \hat{q}$ since $\hat{k}_{i}+\hat{k}_{j}=0$ due to (12). Totally differentiating (11) together with (8) for $i$ and $j$ with respect to $d \tau_{i}$ and applying the symmetry property yields

$$
\begin{gathered}
\tilde{\pi}\left(\hat{q}_{i}-\hat{q}_{j}\right)+q\left[C^{\prime}\left(\hat{Q}_{j}-\hat{Q}_{i}\right)-1\right]=0, \\
\mathcal{X} \hat{Q}+P^{\prime} \hat{q}_{i}-\Psi \hat{Q}_{i}-C^{\prime} \hat{q}_{i}-1=0, \\
\mathcal{X} \hat{Q}+P^{\prime} \hat{q}_{j}-\Psi \hat{Q}_{j}-C^{\prime} \hat{q}_{j}=0 .
\end{gathered}
$$

Defining $\Delta \hat{q}:=\hat{q}_{j}-\hat{q}_{i}$ and $\Delta \hat{Q}:=\hat{Q}_{j}-\hat{Q}_{i}$, we can rewrite $(41)-(43)$ as

$$
\begin{gathered}
-\tilde{\pi} \Delta \hat{q}+q\left(C^{\prime} \Delta \hat{Q}-1\right)=0, \\
2 \mathcal{X} k \hat{q}+P^{\prime} \hat{q}-\Psi k \hat{q}-C^{\prime} \hat{q}-1=0, \\
P^{\prime} \Delta \hat{q}-\Psi \Delta \hat{Q}-C^{\prime} \Delta \hat{q}+1=0,
\end{gathered}
$$

where (45) and (46) follow from adding and subtracting (42) and (43), respectively, and where we used $\hat{Q}=k \hat{q}$. From $(45), \hat{Q}=k \hat{q}$ and $\Gamma=k(\mathcal{X}-\Psi)+P^{\prime}-C^{\prime}$ we obtain

$$
\hat{q}=\frac{1}{\Gamma+k \mathcal{X}}, \quad \hat{Q}=\frac{k}{\Gamma+k \mathcal{X}} .
$$

Using (46) to replace $\Delta \hat{q}$ in (44), solving for $\Delta \hat{Q}$ and inserting back into $\Delta \hat{q}$ gives

$$
\Delta \hat{Q}=\frac{\tilde{\pi}-q\left(P^{\prime}-C^{\prime}\right)}{\tilde{\pi} \Psi-q C^{\prime}\left(P^{\prime}-C^{\prime}\right)}, \quad \Delta \hat{q}=-\frac{q^{2} C^{\prime \prime}}{\tilde{\pi} \Psi-q C^{\prime}\left(P^{\prime}-C^{\prime}\right)} .
$$

In order to complete the proof of (13)-(18), note that we can write

$$
\hat{q}_{i}=\frac{\hat{q}-\Delta \hat{q}}{2}, \quad \hat{Q}_{i}=\frac{\hat{Q}-\Delta \hat{Q}}{2}, \quad \hat{k}_{i}=\frac{\hat{Q}_{i}-k \hat{q}_{i}}{q} .
$$

Inserting (47) and (48) into (49) and into $\hat{q}_{j}=\hat{q}-\hat{q}_{i}, \hat{Q}_{j}=\hat{Q}-\hat{Q}_{i}$ as well as $\hat{k}_{j}=-\hat{k}_{i}$ and rearranging the resulting expressions, it is straightforward to prove (13)-(18). 
Proof of (19) and (20). Equation (20) follows from comparing (10) with (18). To prove $\left.\left(\partial Q_{j} / \partial \tau_{i}\right)\right|_{\text {en }}>\left.\left(\partial Q_{j} / \partial \tau_{i}\right)\right|_{\text {ex }}$ in (19), use (9), (17), $\Omega=(\Gamma+k \mathcal{X})(\Gamma-k \mathcal{X})$ and $\tilde{\Omega}=2(\Gamma+k \mathcal{X})\left[\tilde{\pi} \Psi-q C^{\prime}\left(P^{\prime}-C^{\prime}\right)\right]$, multiply both sides of the inequality by $\Gamma+k \mathcal{X}<0$, $\Gamma-k \mathcal{X}=P^{\prime}-C^{\prime}-k \Psi<0$ and $\tilde{\pi} \Psi-q C^{\prime}\left(P^{\prime}-C^{\prime}\right)>0$ and rearrange. We obtain

$$
\begin{aligned}
\tilde{\pi}\left[(\Gamma-k \mathcal{X})(\Gamma+k \mathcal{X}+k \Psi)+2 k^{2} \mathcal{X} \Psi\right] \\
-q\left(P^{\prime}-C^{\prime}\right)\left[(\Gamma-k \mathcal{X})\left(\Gamma+k \mathcal{X}+k C^{\prime}\right)+2 k^{2} \mathcal{X} C^{\prime}\right]>0 .
\end{aligned}
$$

Taking into account the definitions of $\Gamma$ and $\Psi$, the terms in brackets can be rewritten as $(\Gamma-k \mathcal{X})(\Gamma+k \mathcal{X}+k \Psi)+2 k^{2} \mathcal{X} \Psi=\left(P^{\prime}-C^{\prime}\right)(\Gamma+k \mathcal{X})$ and $(\Gamma-k \mathcal{X})\left(\Gamma+k \mathcal{X}+k C^{\prime}\right)+2 k^{2} \mathcal{X} C^{\prime}=$ $\left(P^{\prime}-C^{\prime}-q k C^{\prime \prime}\right)(\Gamma+k X)$. Inserting into (50) yields

$$
(\Gamma+k \mathcal{X})\left(P^{\prime}-C^{\prime}\right)\left[\tilde{\pi}-q\left(P^{\prime}-C^{\prime}-q k C^{\prime \prime}\right)\right]>0 .
$$

Due to $\Gamma<0, \mathcal{X}<0, P^{\prime}<0, C^{\prime}>0, \tilde{\pi}>0$ and $C^{\prime \prime} \geq 0$, this condition is satisfied, proving $\left.\left(\partial Q_{j} / \partial \tau_{i}\right)\right|_{\text {en }}>\left.\left(\partial Q_{j} / \partial \tau_{i}\right)\right|_{\text {ex }}$. From (20) it finally follows $\left.\left(\partial Q_{i} / \partial \tau_{i}\right)\right|_{\text {en }}<\left.\left(\partial Q_{i} / \partial \tau_{i}\right)\right|_{\text {ex }}$.

Proof of Proposition 1. Define

$$
\begin{aligned}
H(Q) & :=Z^{\prime}(Q)-c-\delta F^{\prime}(1-Q) \\
M(Q ; \varphi, \eta) & :=\varphi(1+\eta) D^{\prime}[(1+\eta) Q] \\
M^{\operatorname{ex}}(Q ; \varphi, \eta) & :=\varphi D^{\prime}[(1+\eta) Q]\left(1+\left.\eta \frac{\partial Q_{j}}{\partial \tau_{i}}\right|_{\mathrm{ex}} /\left.\frac{\partial Q_{i}}{\partial \tau_{i}}\right|_{\mathrm{ex}}\right) .
\end{aligned}
$$

$H(Q)$ is a decreasing function in $Q$ due to $H^{\prime}(Q)=Z^{\prime \prime}(Q)+\delta F^{\prime \prime}(1-Q)<0$, and $M(Q ; \varphi, \eta)$ is non-decreasing in $Q$ since $M_{Q}(Q, \varphi, \eta)=\varphi(1+\eta)^{2} D^{\prime \prime}[(1+\eta) Q] \geq 0$. With the help of (52)-(54), (25) and (27) can be rewritten as, respectively,

$$
H\left(Q^{*}\right)=M\left(Q^{*} ; \varphi, \eta\right), \quad H\left(Q^{\mathrm{ex}}\right)=M^{\mathrm{ex}}\left(Q^{\mathrm{ex}} ; \varphi, \eta\right) .
$$

If $\varphi=0$ or $\eta=0$, (53)-(55) imply $M(Q ; \varphi, \eta)=M^{\operatorname{ex}}(Q ; \varphi, \eta)$ for all $Q$ and, thus, $Q^{\mathrm{ex}}=Q^{*}$, as stated in Proposition 1i. If $\varphi>0$ and $\eta>0$, then $M(Q ; \varphi, \eta)>M^{\mathrm{ex}}(Q ; \varphi, \eta)$ for all $Q$ due to $\left.\left(\partial Q_{i} / \partial \tau_{i}\right)\right|_{\mathrm{ex}}<0$ and $\left.\left(\partial Q_{j} / \partial \tau_{i}\right)\right|_{\mathrm{ex}}>0$ from (9). Since $H$ is decreasing and $M$ non-decreasing in $Q$, it follows that the intersection between $H$ and $M^{\text {ex }}$ is to the right of the intersection between $H$ and $M$, i.e. $Q^{\text {ex }}>Q^{*}$ as stated in Proposition 1 ii. 
In a symmetric situation with $\tau_{i}=\tau_{j}=: \tau$ and $Q_{i}=Q_{j}=: Q$, we can rewrite (8) as

$$
\tau=P(2 Q)+Q P^{\prime}(2 Q) / k-C(Q)-Q C^{\prime}(Q) / k=: G(Q)
$$

Differentiating yields $G^{\prime}(Q)=(2+1 / k) P^{\prime}+2 Q P^{\prime \prime} / k-(1+1 / k) C^{\prime}-Q C^{\prime \prime} / k<0$ due to $P^{\prime}<0, C^{\prime}>0, C^{\prime \prime} \geq 0$ and $P^{\prime}+Q P^{\prime \prime} / k<0$. Hence, $G$ is a decreasing function in $Q$. In case of $\varphi=0$ or $\eta=0$, we have $Q^{*}=Q^{\text {ex }}$ and thereby $\tau^{*}=\tau^{\text {ex }}$, whereas for $\varphi>0$ and $\eta>0, Q^{\mathrm{ex}}>Q^{*}$ implies $\tau^{\mathrm{ex}}<\tau^{*}$. This completes the proof or Proposition 1.

Proof of Proposition 2. Analogous to $M^{\mathrm{ex}}(Q, \varphi, \eta)$ let

$$
M^{\mathrm{en}}(Q ; \varphi, \eta):=\varphi D^{\prime}[(1+\eta) Q]\left(1+\left.\eta \frac{\partial Q_{j}}{\partial \tau_{i}}\right|_{\mathrm{en}} /\left.\frac{\partial Q_{i}}{\partial \tau_{i}}\right|_{\mathrm{en}}\right)
$$

The condition for the Nash equilibrium with endogenous location decision then reads

$$
H\left(Q^{\mathrm{en}}\right)=M^{\mathrm{en}}\left(Q^{\mathrm{en}} ; \varphi, \eta\right)
$$

Obviously, $M^{\mathrm{en}}(Q ; \varphi, \eta)=M^{\mathrm{ex}}(Q ; \varphi, \eta)=M(Q ; \varphi, \eta)$ for all $Q$ if $\varphi=0$ or $\eta=0$. We then obtain Proposition $2 \mathrm{i}$ by the same steps as in the proof of Proposition 1i.

In order to proof Proposition 2ii we show that $M^{\mathrm{en}}(Q, \varphi, \eta)<M^{\mathrm{ex}}(Q, \varphi, \eta)$ for all $Q$ since then the intersection of $M^{\mathrm{en}}(Q, \varphi, \eta)$ with $H(Q)$ is to the right of the intersection of $M^{\mathrm{ex}}(Q, \varphi, \eta)$ with $H(Q)$ and, thus, $Q^{\mathrm{en}}>Q^{\mathrm{ex}}$ and $\tau^{\mathrm{en}}<\tau^{\mathrm{ex}}$ due to $(56)$ and $G^{\prime}(Q)<0$. Using (54) and (57), we obtain $M^{\mathrm{en}}(Q, \varphi, \eta)<M^{\mathrm{ex}}(Q, \varphi, \eta)$ if and only if

$$
\left.\left.\frac{\partial Q_{j}}{\partial \tau_{i}}\right|_{\mathrm{en}} \frac{\partial Q_{i}}{\partial \tau_{i}}\right|_{\mathrm{ex}}<\left.\left.\frac{\partial Q_{j}}{\partial \tau_{i}}\right|_{\mathrm{ex}} \frac{\partial Q_{i}}{\partial \tau_{i}}\right|_{\mathrm{en}}
$$

where all derivatives are evaluated at the same $Q$. Inserting (9), (16) and (17), multiplying with $\Omega \tilde{\Omega} / k<0$, collecting common terms and dividing by $\Gamma+k \mathcal{X}<0$ gives

$$
\tilde{\pi}(\Gamma-k \mathcal{X}+k \Psi)-q\left(P^{\prime}-C^{\prime}\right)\left(\Gamma-k \mathcal{X}+k C^{\prime}\right)<0
$$

Inserting $\Gamma=k(\mathcal{X}-\Psi)+P^{\prime}-C^{\prime}$ and dividing by $P^{\prime}-C^{\prime}<0$, condition (60) reduces to

$$
\tilde{\pi}-q\left(P^{\prime}-C^{\prime}-k q C^{\prime \prime}\right)>0
$$

Condition (61) is satisfied due to $\tilde{\pi}>0, P^{\prime}<0, C^{\prime}>0$ and $C^{\prime \prime} \geq 0$. 


\section{References}

Aichele, R. And G. Felbermayr (2015): "Kyoto and Carbon Leakage: An Empirical Analysis of the Carbon Content of Bilateral Trade," Review of Economics and Statistics, 97, 104-115.

Aitken, B., A. Harrison, And R. E. Lipsey (1996): "Wages and Foreign Ownership: A Comparative Study of Mexico, Venezuela, and the United States," Journal of International Economics, 40, 345-371.

Azar, J., I. Marinescu, And M. I. Steinbaum (2017): "Labor Market Concentration," National Bureau of Economic Research Working Paper Series, No. 24147.

Azar, J. A., I. Marinescu, M. I. Steinbaum, And B. Taska (2018): "Concentration in US Labor Markets: Evidence From Online Vacancy Data," National Bureau of Economic Research Working Paper Series, No. 24395.

Babiker, M. H. (2005): "Climate Change Policy, Market Structure, and Carbon Leakage," Journal of International Economics, 65, 421-445.

Barnett, A. H. (1980): "The Pigouvian Tax Rule Under Monopoly," The American Economic Review, 70, 1037-1041.

BARretT, S. (1994): "Strategic Environmental Policy and International Trade," Journal of Public Economics, 54, 325-338.

Brander, J. A. (1995): "Strategic Trade Policy," in Handbook of International Economics, ed. by G. Grossman and K. Rogoff, Elsevier Science B.V., vol. III.

Brander, J. A. And B. J. Spencer (1985): "Export Subsidies and International Market Share Rivalry," Journal of International Economics, 18, 83-100.

Buchanan, J. M. (1969): "External Diseconomies, Corrective Taxes, and Market Structure," The American Economic Review, 59, 174-177.

Conrad, K. (1993): "Taxes and Subsidies for Pollution-Intensive Industries as Trade Policy," Journal of Environmental Economics and Management, 25, 121-135. 
Duval, Y. And S. F. Hamilton (2002): "Strategic Environmental Policy and International Trade in Asymmetric Oligopoly Markets," International Tax and Public Finance, 9, 259-271.

EBert, U. (1992): "Pigouvian Tax and Market Structure: The Case of Oligopoly and Different Abatement Technologies," FinanzArchiv / Public Finance Analysis, 49, 154166.

EichneR, T. AND M. Runkel (2012): "Interjurisdictional Spillovers, Decentralized Policymaking, and the Elasticity of Capital Supply," American Economic Review, 102, $2349-57$.

_ (2014): "Subsidizing Renewable Energy under Capital Mobility," Journal of Public Economics, 117, 50-59.

Felder, S. And T. F. Rutherford (1993): "Unilateral $\mathrm{CO}_{2}$ Reductions and Carbon Leakage: The Consequences of International Trade in Oil and Basic Materials," Journal of Environmental Economics and Management, 25, 162-176.

Girma, S., D. Greenaway, and K. Wakelin (2001): "Who Benefits from Foreign Direct Investment in the UK?" Scottish Journal of Political Economy, 48, 119-133.

Hamilton, S. F. And T. Requate (2004): "Vertical Structure and Strategic Environmental Trade Policy," Journal of Environmental Economics and Management, 47, 260-269.

Haufler, A. And I. Wooton (2010): "Competition for Firms in an Oligopolistic Industry: The Impact of Economic Integration," Journal of International Economics, 80, 239-248.

Helm, C. And R. C. Schmidt (2015): "Climate Cooperation with Technology Investments and Border Carbon Adjustment." European Economic Review, 75, 112-130.

Hoel, M. (1997): "Environmental Policy with Endogenous Plant Locations," Scandinavian Journal of Economics, 99, 241-259.

Hung, N. (1994): "Taxing Pollution in an International Duopoly Context," Economics Letters, 44, 339-343. 
IPCC (2018): "Global warming of $1.5^{\circ} \mathrm{C}$. An IPCC Special Report on the impacts of global warming of $1.5^{\circ} \mathrm{C}$ above pre-industrial levels and related global greenhouse gas emission pathways, in the context of strengthening the global response to the threat of climate change, sustainable development, and efforts to eradicate poverty," Intergovernmental Panel on Climate Change, Geneva, Switzerland.

Kennedy, P. W. (1994): "Equilibrium Pollution Taxes in Open Economies with Imperfect Competition," Journal of Environmental Economics and Management, 27, 49-63.

Lipsey, R. E. AND F. SJÖHOLM (2004): "Foreign Direct Investment, Education and Wages in Indonesian Manufacturing," Journal of Development Economics, 73, 415-422.

Markusen, J. R., E. R. Morey, And N. D. Olewiler (1993): "Environmental Policy when Market Structure and Plant Locations are Endogenous," Journal of Environmental Economics and Management, 24, 69-86.

(1995): "Competition in Regional Environmental Policies when Plant Locations are Endogenous," Journal of Public Economics, 56, 55-77.

Menegatti, M. (2001): "On the Conditions for Precautionary Saving," Journal of Economic Theory, 98, 189-193.

Oates, W. E. And R. M. Schwab (1988): "Economic Competition among Jurisdictions: Efficiency Enhancing or Distortion Inducing?" Journal of Public Economics, 35, $333-354$.

OgawA, H. And D. E. Wildasin (2009): "Think Locally, Act Locally: Spillovers, Spillbacks, and Efficient Decentralized Policymaking," American Economic Review, 99, $1206-17$.

Rauscher, M. (1995): "Environmental Regulation and the Location of Polluting Industries," International Tax and Public Finance, 2, 229-244.

Requate, T. (1997): "Green Taxes in Oligopoly if the Number of Firms is Endogenous," FinanzArchiv / Public Finance Analysis, 54, 261-280.

(2006): "Environmental Policy under Imperfect Competition," in The international yearbook of environmental and resource economics: A survey of current issues., 
ed. by H. Folmer and T. Tietenberg, Edward Elgar Pub, New Horizon of Environmental Economics, 120-207.

Sturm, D. M. (2003): "Trade and the Environment: A Survey of the Literature," in Environmental Policy in an International Perspective, ed. by L. Marsiliani, M. Rauscher, and C. Withagen, Kluwer Academic Publisher, 119-149.

Tomohara, A. and S. Takil (2011): "Does Globalization Benefit Developing Countries? Effects of FDI on Local Wages," Journal of Policy Modeling, 33, 511-521. 


\section{Online Appendix}

Second-order condition, reaction functions and stability in the $Y$-sector. The first-order condition (8) of profit maximization of firm $\ell$ in country $i$ can be written as

$$
\begin{aligned}
\frac{d \pi_{i \ell}}{d q_{i \ell}}=P\left(Q_{i,-\ell}+q_{i \ell}+Q_{j}\right) & +q_{i \ell} P^{\prime}\left(Q_{i,-\ell}+q_{i \ell}+Q_{j}\right) \\
& -C\left(Q_{i,-\ell}+q_{i \ell}\right)-q_{i \ell} C^{\prime}\left(Q_{i,-\ell}+q_{i \ell}\right)-\tau_{i}=0 .
\end{aligned}
$$

This equation determines the reaction function of firm $\ell$ in country $i$. The slope with respect to output of the firm's competitors from country $i$ and $j$ read, respectively,

$$
\begin{aligned}
\frac{\partial q_{i \ell}}{\partial Q_{i,-\ell}} & =-\frac{P^{\prime}+q_{i \ell} P^{\prime \prime}-C^{\prime}-q_{i \ell} C^{\prime \prime}}{2 P^{\prime}+q_{i \ell} P^{\prime \prime}-2 C^{\prime}-q_{i \ell} C^{\prime \prime}}, \\
\frac{\partial q_{i \ell}}{\partial Q_{j}} & =-\frac{P^{\prime}+q_{i \ell} P^{\prime \prime}}{2 P^{\prime}+q_{i \ell} P^{\prime \prime}-2 C^{\prime}-q_{i \ell} C^{\prime \prime}} .
\end{aligned}
$$

Our assumption $P^{\prime}+q_{i \ell} P^{\prime \prime}<0$ together with $P^{\prime}<0, C^{\prime}>0$ and $C^{\prime \prime}>0$ ensures a negative sign of the common denominator of (63) and (64), which equals the second derivative of the firm's profit function, $d^{2} \pi_{i \ell} / d q_{i \ell}^{2}$. Hence, the second-order condition for profit maximization is satisfied. Moreover, since $P^{\prime}+q_{i \ell} P^{\prime \prime}<0$ also renders the numerators of (63) and (64) negative, the reaction function is decreasing in $Q_{i,-\ell}$ and $Q_{j}$, reflecting the case of strategic substitutes. Finally, the condition $P^{\prime}+q_{i \ell} P^{\prime \prime}<0$ ensures that (63) and (64) are larger than -1 , implying stability of the Nash equilibrium. All these properties are not guaranteed if, in contrast to our assumption, we suppose $P^{\prime}+q_{i \ell} P^{\prime \prime} \geq 0$.

Autarky versus free trade. With the demand function $\widetilde{P}\left(Q_{i}\right)$ and the wage rate given by (6), firm $\ell$ 's profit in sector $Y$ of country $i$ under autarky can be written as

$$
\pi_{i \ell}=\left[\widetilde{P}\left(Q_{i,-\ell}+q_{i \ell}\right)-C\left(Q_{i,-\ell}+q_{i \ell}\right)-\tau_{i}\right] q_{i \ell}
$$

The first-order condition of profit maximization, evaluated at a symmetric solution, is

$$
\widetilde{P}\left(k q_{i}\right)+q_{i} \widetilde{P}^{\prime}\left(k q_{i}\right)-C\left(k q_{i}\right)-q_{i} C^{\prime}\left(k q_{i}\right)-\tau_{i}=0 .
$$

Applying the implicit function theorem and defining $\widetilde{\Gamma}:=k\left(\widetilde{P}^{\prime}+q \widetilde{P}^{\prime \prime}-\Psi\right)+\widetilde{P}^{\prime}-C^{\prime}<0$, we immediately obtain $\left.\left(\partial q_{i} / \partial \tau_{i}\right)\right|_{\text {aut }}=1 / \widetilde{\Gamma}<0,\left.\left(\partial Q_{i} / \partial \tau_{i}\right)\right|_{\text {aut }}=k / \widetilde{\Gamma}<0$ and $\left.\left(\partial q_{j} / \partial \tau_{i}\right)\right|_{\text {aut }}=$ $\left.\left(\partial Q_{j} / \partial \tau_{i}\right)\right|_{\text {aut }}=0$. Welfare in country $i$ is again given by (22). As under free trade, we 
have $w_{i}=C\left(Q_{i}\right), \Pi_{i}^{x}=\delta F\left(1-Q_{i}\right)+\left[c-C\left(Q_{i}\right)\right]\left(1-Q_{i}\right)$ and $T_{i}=\tau_{i} Q_{i}$. But profit in sector $Y$ and the household's expenditures for good $Y$ have to be replaced by, respectively, $\Pi_{i}^{y}=\left[\widetilde{P}\left(Q_{i}\right)-C\left(Q_{i}\right)-\tau_{i}\right] Q_{i}$ and $p y_{i}=Q_{i} \widetilde{P}\left(Q_{i}\right)$. Inserting into (22) gives (33).

To compare non-cooperation under autarky and free trade, note that the equilibrium condition (34) under autarky can be rewritten as

$$
H\left(Q^{\text {aut }}\right)=\varphi D^{\prime}\left[(1+\eta) Q^{\text {aut }}\right]
$$

The equilibrium condition under free trade is given by $(27)$ or, equivalently, $H\left(Q^{\mathrm{ex}}\right)=$ $M^{\mathrm{ex}}\left(Q^{\mathrm{ex}}, \varphi, \eta\right)$ in (55). Due to (54), it is obvious that $M^{\mathrm{ex}}(Q ; \varphi, \eta)<\varphi D^{\prime}[(1+\eta) Q]$ for all $Q$. Since $H^{\prime}<0$, it immediately follows that $Q^{\text {aut }}<Q^{\text {ex }}$ and, by $(56), \tau^{\text {aut }}>\tau^{\mathrm{ex}}$.

Endogenous versus exogenous wage rate. If $Z(\cdot)$ and $F(\cdot)$ are both quadratic, then $P(\cdot)=Z^{\prime}(\cdot)$ and $C(\cdot)=c+\delta F^{\prime}(\cdot)$ are both linear. Hence, $P^{\prime}(\cdot)=Z^{\prime \prime}(\cdot)$ and $C^{\prime}(\cdot)=$ $-\delta F^{\prime \prime}(\cdot)$ are both constant and we obtain $P^{\prime \prime}(\cdot)=C^{\prime \prime}(\cdot)=0$. Using this specification together with the definition of $\mathcal{X}$, condition (25) of the efficient solution and condition (27) of the Nash policy equilibrium can be rewritten as, respectively,

$$
\begin{aligned}
\widetilde{H}\left(Q^{*}, \delta\right) & =\varphi(1+\eta) D^{\prime}\left[(1+\eta) Q^{*}\right], \\
\widetilde{H}\left(Q^{\mathrm{ex}}, \delta\right) & =\varphi D^{\prime}\left[(1+\eta) Q^{\mathrm{ex}}\right]\left(1-\eta \frac{k Z^{\prime \prime}}{(k+1)\left(Z^{\prime \prime}+\delta F^{\prime \prime}\right)}\right)
\end{aligned}
$$

where

$$
\widetilde{H}(Q, \delta):=Z^{\prime}(Q)-c-\delta F^{\prime}(1-Q)
$$

Note that $\widetilde{H}_{Q}(Q, \delta)=Z^{\prime \prime}(Q)+\delta F^{\prime \prime}(1-Q)<0$. Moreover, $\widetilde{H}(Q, \delta)<\widetilde{H}(Q, 0)$ and $\widetilde{H}_{Q}(Q, \delta)<\widetilde{H}_{Q}(Q, 0)$ for all $Q$ and $\delta>0$, due to $F^{\prime}>0$ and $F^{\prime \prime}<0$. Hence, the function $\widetilde{H}$ is decreasing in $Q$, and moving from an exogenous wage rate $(\delta=0)$ to an endogenous wage rate $(\delta>0)$ moves $\widetilde{H}$ downwards and makes it steeper.

Next denote the difference between the RHS of (68) and the RHS of (69), both evaluated at the same $Q$, as $R(Q, \delta)$. Rearranging yields

$$
R(Q, \delta)=\eta \varphi D^{\prime}[(1+\eta) Q] \frac{(2 k+1) Z^{\prime \prime}+(k+1) \delta F^{\prime \prime}}{(k+1)\left(Z^{\prime \prime}+\delta F^{\prime \prime}\right)} .
$$

Differentiating yields

$$
R_{Q}(Q, \delta)=\eta(1+\eta) \varphi D^{\prime \prime}[(1+\eta) Q] \frac{(2 k+1) Z^{\prime \prime}+(k+1) \delta F^{\prime \prime}}{(k+1)\left(Z^{\prime \prime}+\delta F^{\prime \prime}\right)}>0
$$




$$
R_{\delta}(Q, \delta)=-\eta \varphi D^{\prime}[(1+\eta) Q] \frac{k(k+1) Z^{\prime \prime} F^{\prime \prime}}{(k+1)^{2}\left(Z^{\prime \prime}+\delta F^{\prime \prime}\right)^{2}}<0 .
$$

Hence, for given $\delta$, the gap between the RHS of (68) and the RHS of (69) is increasing in $Q$, as shown by (72). And for any given $Q$, moving from an exogenous wage rate $(\delta=0)$ to an endogenous wage rate $(\delta>0)$ reduces the gap between the RHS of $(68)$ and the RHS of (69), as shown by (73). Combining these insights with the properties of $\widetilde{H}$ implies that $Q^{\text {ex }}-Q^{*}$ is smaller for an endogenous wage rate than for an exogenous wage rate.

Model with third country. In order to compare the non-cooperative equilibrium with the policy under full cooperation, rewrite (38) and (40) as

$$
\begin{aligned}
\widehat{H}\left(Q^{*}\right) & =0 \\
\widehat{H}\left(\widehat{Q}^{\mathrm{ex}}\right) & =-\widehat{Q}^{\mathrm{ex}} Z^{\prime \prime}\left(2 \widehat{Q}^{\mathrm{ex}}\right)\left(\left.\frac{\partial Q_{i}}{\partial \tau_{i}}\right|_{\widehat{\mathrm{ex}}}+\left.\frac{\partial Q_{j}}{\partial \tau_{i}}\right|_{\widehat{\mathrm{ex}}}\right) /\left.\frac{\partial Q_{i}}{\partial \tau_{i}}\right|_{\widehat{\mathrm{ex}}} .
\end{aligned}
$$

with $\widehat{H}(Q):=Z^{\prime}(2 Q)-c-\delta F^{\prime}(1-Q)$ and $\widehat{H}^{\prime}(Q):=2 Z^{\prime \prime}(2 Q)+\delta F^{\prime \prime}(1-Q)<0$, so $\widehat{H}(Q)$ is decreasing in $Q$. Since $Z^{\prime \prime}(\cdot)<0,\left.\left(\partial Q_{i} / \partial \tau_{i}\right)\right|_{\widehat{\mathrm{ex}}}<0$ and $\left.\left[\partial\left(Q_{i}+Q_{j}\right) / \partial \tau_{i}\right]\right|_{\widehat{\mathrm{ex}}}<0$, the RHS of (75) is positive and in comparison with (74) implies $\widehat{Q}^{\text {ex }}<\widehat{Q}^{*}$. Using the first-order condition of profit maximization gives $\tau=\widehat{P}(2 Q)+Q \widehat{P}^{\prime}(2 Q) / k-C(Q)-Q C^{\prime}(Q) / k=$ : $\widehat{G}(Q)$ with $\widehat{G}^{\prime}(Q)=(2+1 / k) \widehat{P}^{\prime}+2 Q \widehat{P}^{\prime \prime} / k-(1+1 / k) C^{\prime}-Q C^{\prime \prime} / k<0$. From $\widehat{Q}^{\text {ex }}<\widehat{Q}^{*}$ it then follows $\widehat{\tau}^{\mathrm{ex}}>\widehat{\tau}^{*}$. In order to compare the Nash policy equilibrium with the policy chosen under partial cooperation, rewrite condition (39) under partial cooperation as

$$
\widehat{H}\left(\widehat{Q}^{* *}\right)=-2 \widehat{Q}^{* *} Z^{\prime \prime}\left(2 \widehat{Q}^{* *}\right) .
$$

Due to $Z^{\prime \prime}(\cdot)<0,\left.\left[\partial\left(Q_{i}+Q_{j}\right) / \partial \tau_{i}\right]\right|_{\widehat{\mathrm{ex}}}<0,\left.\left(\partial Q_{i} / \partial \tau_{i}\right)\right|_{\widehat{\mathrm{ex}}}<0$ and $\left.\left(\partial Q_{j} / \partial \tau_{i}\right)\right|_{\widehat{\mathrm{ex}}}>0$, the RHS of (76) is larger than the RHS of (75), implying $\widehat{Q}^{\text {ex }}>\widehat{Q}^{* *}$ and $\widehat{\tau}^{\text {ex }}<\widehat{\tau}^{* *}$.

The import externality can be computed from (36) as

$$
\mathrm{IE}:=\frac{\partial \widehat{V}^{C}\left(Q_{i}, Q_{j}\right)}{\partial \tau_{i}}=-2 \widehat{Q}^{\mathrm{ex}} Z^{\prime \prime}\left(2 \widehat{Q}^{\mathrm{ex}}\right)\left(\left.\frac{\partial Q_{i}}{\partial \tau_{i}}\right|_{\widehat{\mathrm{ex}}}+\left.\frac{\partial Q_{j}}{\partial \tau_{i}}\right|_{\widehat{\mathrm{ex}}}\right)<0 .
$$

Differentiating $\widehat{V}\left(Q_{j}, Q_{i}\right)$ defined analogous to (37), the export externality reads

$$
\mathrm{EE}:=\frac{\partial \widehat{V}\left(Q_{j}, Q_{i}\right)}{\partial \tau_{i}}=\left.\left[Z^{\prime}\left(2 \widehat{Q}^{\mathrm{ex}}\right)-c-\delta F^{\prime}\left(1-\widehat{Q}^{\mathrm{ex}}\right)\right] \frac{\partial Q_{j}}{\partial \tau_{i}}\right|_{\widehat{\mathrm{ex}}}
$$




$$
+\widehat{Q}^{\mathrm{ex}} Z^{\prime \prime}\left(2 \widehat{Q}^{\mathrm{ex}}\right)\left(\left.\frac{\partial Q_{i}}{\partial \tau_{i}}\right|_{\widehat{\mathrm{ex}}}+\left.\frac{\partial Q_{j}}{\partial \tau_{i}}\right|_{\widehat{\mathrm{ex}}}\right)
$$

Using (40) in order to replace $Z^{\prime}-c-\delta F^{\prime}$ and rearranging, we obtain

$$
\mathrm{EE}=\widehat{Q}^{\mathrm{ex}} Z^{\prime \prime}\left(2 \widehat{Q}^{\mathrm{ex}}\right)\left(\left.\frac{\partial Q_{i}}{\partial \tau_{i}}\right|_{\widehat{\mathrm{ex}}}+\left.\frac{\partial Q_{j}}{\partial \tau_{i}}\right|_{\widehat{\mathrm{ex}}}\right)\left(\left.\frac{\partial Q_{i}}{\partial \tau_{i}}\right|_{\widehat{\mathrm{ex}}}-\left.\frac{\partial Q_{j}}{\partial \tau_{i}}\right|_{\widehat{\mathrm{ex}}}\right) /\left.\frac{\partial Q_{i}}{\partial \tau_{i}}\right|_{\widehat{\mathrm{ex}}}>0
$$

In order to compare the non-cooperative case with full cooperation, we have to add IE and EE. After some rearrangements, we obtain

$$
\mathrm{IE}+\mathrm{EE}=-\widehat{Q}^{\mathrm{ex}} Z^{\prime \prime}\left(2 \widehat{Q}^{\mathrm{ex}}\right)\left(\left.\frac{\partial Q_{i}}{\partial \tau_{i}}\right|_{\widehat{\mathrm{ex}}}+\left.\frac{\partial Q_{j}}{\partial \tau_{i}}\right|_{\widehat{\mathrm{ex}}}\right)^{2} /\left.\frac{\partial Q_{i}}{\partial \tau_{i}}\right|_{\widehat{\mathrm{ex}}}<0,
$$

and, thus, inefficient overtaxation. In comparison with partial cooperation, only the positive export externality EE matters. We then obtain inefficient undertaxation. 